\title{
Respirometric In Situ Methods for Real-Time Monitoring of Corrosion Rates: Part II. Immersion
}

\author{
M. G. Strebl, ${ }^{*}$ (i) M. P. Bruns, (i) G. Schulze, and S. Virtanen ${ }^{* *, z_{(1)}}$ \\ Department of Materials Science (LKO, WW-4), University of Erlangen-Nuremberg, 91058 Erlangen, Germany
}

\begin{abstract}
With the aim to open a new window into corrosion processes this paper presents respirometric methods for real-time in situ monitoring of corrosion rates under immersion conditions. With these techniques, sensitive, non-destructive corrosion rate measurements are possible on basically all metals and alloys. Different methods are presented that enable to monitor HER, ORR or both reactions simultaneously based on the amount of evolved $\mathrm{H}_{2}$ or the amount of consumed $\mathrm{O}_{2}$ by volumetric, manometric and sensor-based approaches. Various research examples are presented, demonstrating the benefits and limitations of the different approaches. For Mg alloys, besides HER, ORR plays a role in the cathodic reactions and a good correlation of the total cathodic charge with mass loss was obtained. $\mathrm{H}_{2}$ dissolution into the electrolyte was identified as an important factor. The results obtained for $\mathrm{Zn}$ immersion corrosion in intermittent-flow and flow-through respirometric experiments suggest that the ORR mechanism leads to the generation of stable $\mathrm{H}_{2} \mathrm{O}_{2}$ under these conditions. As a result, the effective number of exchanged electrons for one $\mathrm{O}_{2}$ molecule was found to be in between two and four. The here introduced respirometric techniques allow new insights into corrosion mechanisms, in addition to enabling real-time monitoring of corrosion.

(C) 2021 The Author(s). Published on behalf of The Electrochemical Society by IOP Publishing Limited. This is an open access article distributed under the terms of the Creative Commons Attribution Non-Commercial No Derivatives 4.0 License (CC BYNC-ND, http://creativecommons.org/licenses/by-nc-nd/4.0/), which permits non-commercial reuse, distribution, and reproduction in any medium, provided the original work is not changed in any way and is properly cited. For permission for commercial reuse, please email: permissions@ioppublishing.org. [DOI: 10.1149/1945-7111/abdb4a]
\end{abstract}

Manuscript submitted November 20, 2020; revised manuscript received January 12, 2021. Published January 22, 2021. This paper is part of the JES Focus Issue on Characterization of Corrosion Processes in Honor of Philippe Marcus.

Supplementary material for this article is available online

This paper is the second of a series that describes the use of respirometric approaches in corrosion science. While Part I covered techniques to monitor atmospheric corrosion in real-time, ${ }^{1}$ this part is focused on immersion conditions. In Part III respirometric methods will be combined with electrochemical measurements and the methods will be applied to follow changes of the immersion conditions in real-time, directly on the same sample.

Full immersion conditions are frequently used to study corrosion of metallic materials. One advantage of immersion tests is that the bulk electrolyte facilitates the use of electrochemical techniques to characterize a corrosion process. The methods employed range from macroscopic electrochemical techniques like potentiodynamic polarization (PP), linear polarization resistance measurements (LPR), electrochemical impedance spectroscopy (EIS) and electrochemical noise measurements $(\mathrm{EN})$ to localized electrochemical techniques like scanning vibrating electrode (SVET), scanning droplet cell (SDC), and others. Each technique shows different possibilities and limitations and a complementary approach is useful to reveal many details about the studied corrosion system. ${ }^{2}$

Additionally, non-electrochemical techniques are commonly used to quantify the amount of corrosion that occurs during immersion. This includes the gravimetric determination of mass loss after removal of the corrosion products with a suitable pickling solution. ${ }^{3}$ The quartz crystal microbalance (QCM) can be used to monitor mass changes with a high resolution in situ. ${ }^{4,5}$ Another approach is the detection of metallic cations released into the immersion electrolyte by solution analysis, e.g. with ion chromatography (IC), ${ }^{6}$ inductively coupled plasma atomic emission spectroscopy (ICP-AES), or mass spectrometry (ICP-MS). Sophisticated in-line techniques for both ICP-AES ${ }^{7,8}$ and ICP-MS ${ }^{9,10}$ have been developed that allow for monitoring of time- and potential-resolved elemental dissolution rates. While insoluble species that form a corrosion product film are undetectable by ICP-AES, there are cases where the amount of insoluble ions may be quantified indirectly by a mass-charge balance during galvanostatic experiments. ${ }^{8}$

While some of the methods mentioned above are destructive and only give information at a distinct point in time (PP) or the cumulative

\footnotetext{
*Electrochemical Society Student Member.

**Electrochemical Society Fellow.

${ }^{\mathrm{z}}$ E-mail: virtanen@ww.uni-erlangen.de
}

or historical amount of corrosion that has occurred (mass loss, off-line solution analysis), other methods are capable of monitoring the corrosion process in the time domain (LPR, EIS, EN, QCM, in-line spectrometry). However, to extract reliable corrosion rates with these methods is not without pitfalls. For example, in PP, significant variability of the results comes from the selection of the linear regions where to perform the Tafel fit. Influence of mixed activation control and diffusion control can be an issue, ${ }^{11}$ as well as contributions of ohmic drop $^{12}$ that are difficult to assess accurately. Additionally, it is required to polarize the sample far away from its free corrosion potential in order to determine the correct Tafel slopes. This strong polarization can lead to changes induced on the sample surface that can affect the results. The alkalinization related with cathodic reactions can artificially increase or decrease the dissolution rate. Therefore, it can make a difference whether the scan is started at a cathodic potential or at the corrosion potential. ${ }^{13}$ For $\mathrm{Mg}$, it was found that Tafel extrapolation from the cathodic polarization initiated at the corrosion potential provides a good estimate of the corrosion rate while starting the potential scan at a cathodic potential leads to substantial underestimation of the corrosion current. ${ }^{14}$ For Al, cathodic dissolution can occur during the cathodic scan as a consequence of the produced $\mathrm{OH}^{-}$ that attacks the native oxide film. ${ }^{13,15-17}$

The interpretation of data generated with EIS or LPR can be challenging as well. A suitable electrical equivalent circuit that represents the correct physicochemical processes of the corroding electrochemical interface is needed for the extraction of a polarization resistance value. The polarization resistance, obtained from fitting EIS data to an equivalent circuit or from LPR measurements, can be inserted into the Stern-Geary equation to obtain instantaneous corrosion rate information. For this however, the Tafel slopes are another required input that has to be determined with independent experiments. ${ }^{18}$ Changes of these values with time are usually not considered which makes interpretation of data from the Stern-Geary method difficult. ${ }^{19}$ Another issue complicating EIS measurements is the intrinsic non-stationarity of a corrosion process that is most severe in the time directly after immersing the sample. ${ }^{2}$

Respirometry is a widespread method used in many research disciplines to quantify metabolic rates associated with the respiration of animals, ${ }^{20,21}$ plants, ${ }^{22,23}$ tissues, ${ }^{24}$ cells, ${ }^{25}$ or microorganisms. ${ }^{26}$ Metabolic processes in a biochemical sense are redox reactions that involve the transfer of electrons from donor molecules (e.g. organic 
compound) to an electron acceptor (e.g. $\mathrm{O}_{2}$ ) in order to provide the organism with energy. ${ }^{26}$ The respirometric principle is based on measuring the rate of the reduction reaction associated with this metabolic conversion process. ${ }^{26}$ For example, the consumption of $\mathrm{O}_{2}$ by a fish in a sealed chamber can be measured to characterize its metabolism under different conditions. ${ }^{27}$ In a way, corrosion is a similar redox process that is composed of an anodic metal oxidation reaction and a cathodic reduction reaction that occur at an equal rate on the corroding surface. The aim of this paper is to demonstrate that similar respirometric approaches can be employed to monitor corrosion rates under immersion conditions non-destructively and in real-time by monitoring the rate of the cathodic reactions. Different methods to assess the rate of the $\mathrm{O}_{2}$ reduction reaction $(\mathrm{ORR})^{28-30}$ or the $\mathrm{H}_{2}$ evolution reaction (HER) ${ }^{14,31,32}$ of immersed samples have been presented before. However, the use of this universal approach, that is applicable in principle to all metals or alloys, ${ }^{30}$ in quantitative corrosion studies remained below its potential. This paper gives an overview of the different approaches and additionally presents new methods that enable one to monitor ORR, HER or both reactions simultaneously. Furthermore, it is intended to highlight details in the experimental setups that are necessary to avoid typical pitfalls and to get reliable results. The possibility to apply the method to study biodegradable metals in different simulated physiological solutions is shown. Examples of measurements with different respirometric methods will be presented and are compared with independent mass loss measurements.

\section{Respirometric Approach}

As described in Part I of this paper series, the measurement principle of the respirometric method is to monitor the rates of the most important cathodic reactions (HER and ORR) based on the measurement of the rates of $\mathrm{O}_{2}$ consumption or $\mathrm{H}_{2}$ evolution. In the HER protons are reduced to $\mathrm{H}_{2}$ gas (Eq. 1).

$$
\begin{gathered}
2 \boldsymbol{H}^{+}+2 \boldsymbol{e}^{-} \leftrightharpoons \boldsymbol{H}_{2} \quad E_{0}=0 V_{S H E} \\
\boldsymbol{O}_{2}+4 \boldsymbol{H}^{+}+4 \boldsymbol{e}^{-} \leftrightharpoons 2 \boldsymbol{H}_{2} \boldsymbol{O} \quad E_{0}=1.229 V_{S H E}
\end{gathered}
$$

$$
\begin{gathered}
\boldsymbol{O}_{2}+2 \boldsymbol{H}^{+}+2 \boldsymbol{e}^{-} \leftrightharpoons \boldsymbol{H}_{2} \boldsymbol{O}_{2} \quad E_{0}=0.67 V_{S H E} \\
\boldsymbol{H}_{2} \boldsymbol{O}_{2}+2 \boldsymbol{H}^{+}+2 \boldsymbol{e}^{-} \leftrightharpoons 2 \boldsymbol{H}_{2} \boldsymbol{O} \quad E_{0}=1.77 V_{S H E} \\
2 \boldsymbol{H}_{2} \boldsymbol{O}_{2} \leftrightharpoons 2 \boldsymbol{H}_{2} \boldsymbol{O}+\boldsymbol{O}_{2}
\end{gathered}
$$

The mechanism of the ORR, which involves several elementary steps and reaction intermediates, has been controversially discussed and is still not completely resolved. ${ }^{33}$ According to a simplified reaction scheme, ${ }^{34}$ the reduction of $\mathrm{O}_{2}$ can progress by two alternative pathways depending on the electrocatalytic material where the reaction takes place. ${ }^{35-37} \mathrm{O}_{2}$ can be reduced in a direct 4-electron mechanism (Eq. 2) to $\mathrm{H}_{2} \mathrm{O}$ without any detectable intermediates. The parallel peroxide pathway includes the reduction of $\mathrm{O}_{2}$ to $\mathrm{H}_{2} \mathrm{O}_{2}$ as an intermediate (Eq. 3), that can be followed by a further reduction of the peroxide (Eq. 4) or by decomposition of two $\mathrm{H}_{2} \mathrm{O}_{2}$ molecules via a disproportionation reaction (Eq. 5) to $\mathrm{O}_{2}$ and $\mathrm{H}_{2} \mathrm{O}$. Alternatively, $\mathrm{H}_{2} \mathrm{O}_{2}$ can be transported to the bulk solution. Hence, for the ORR, the effective number of exchanged electrons $\mathrm{z}_{\mathrm{ORR}}$ can range between $\mathrm{z}_{\mathrm{ORR}}=2$ (incomplete reduction with only reaction 3 ) and $z_{O R R}=4$ (direct reduction or complete reduction with a combination of reactions $3+4$ or $3+5){ }^{37}$ As a consequence, the number of metal ions that can be oxidized by one $\mathrm{O}_{2}$ molecule can vary by a factor of two which contributes uncertainty to ORR rates calculated from $\mathrm{O}_{2}$ consumption rates.

The respirometric measurement approaches discussed in this work for immersion can be categorized in volumetric techniques, manometric techniques or the measurement of partial pressure or concentration with a sensor (Fig. 1). In the volumetric approach, changes in gas volume are detected at ambient pressure, while in the manometric approach changes in pressure are measured in constant volume chambers. As opposed to atmospheric corrosion, a bulk liquid phase is present in immersion conditions. The species dissolved in this phase have to be taken into account, when determining the rate of consumption of $\mathrm{O}_{2}$ or the rate of production of $\mathrm{H}_{2}$ that accompanies a corrosion process. Some techniques that
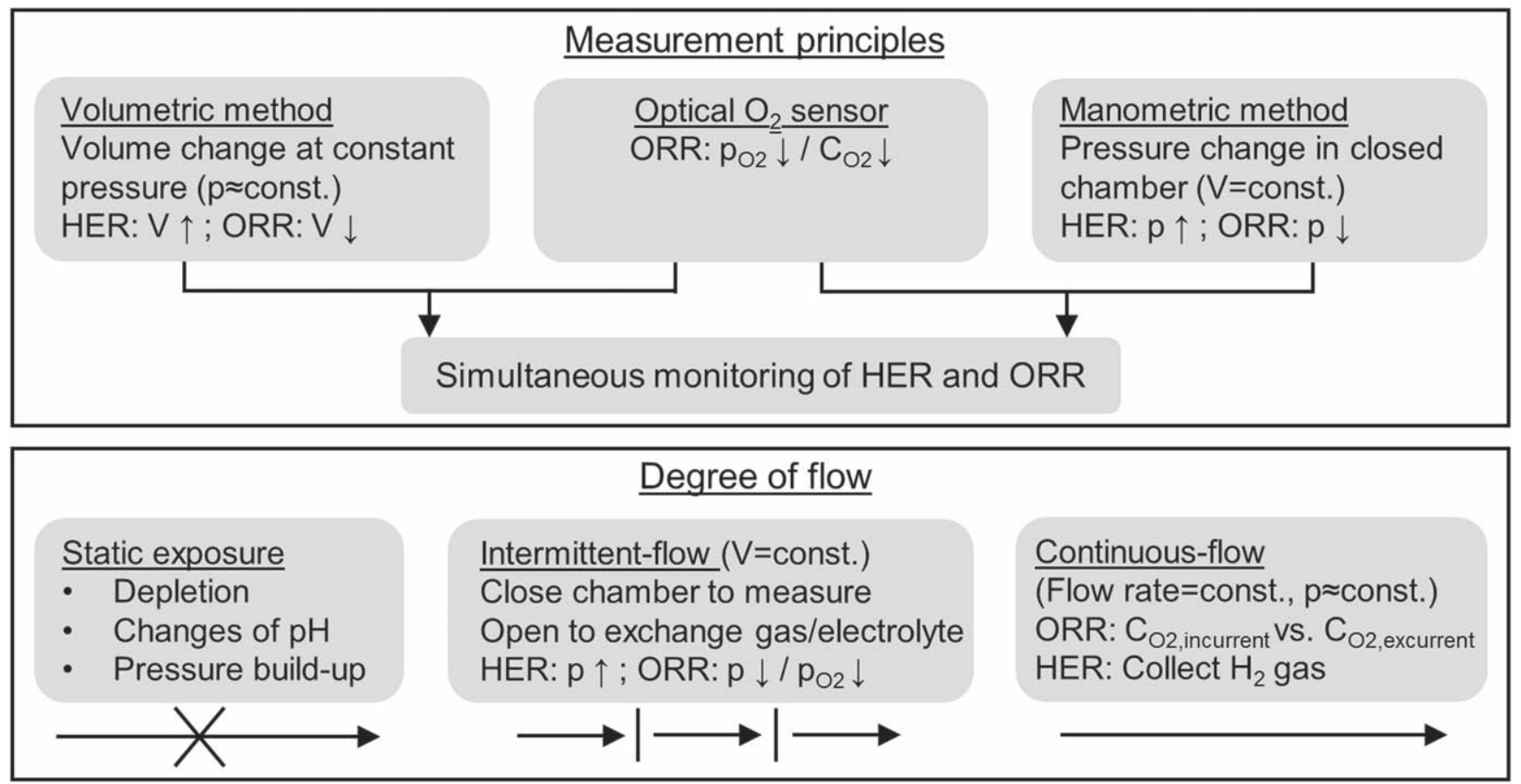

Figure 1. Classification of respirometric approaches to monitor immersion corrosion kinetics by the measurement principle and the degree of flow. Arrows in the lower part of the figure visualize the degree of flow through the respirometric chamber for the different measurement approaches. Adapted from Ref. 1. 
will be presented require the presence of a gas headspace above the liquid phase. The partial pressure of $\mathrm{O}_{2}$ and $\mathrm{H}_{2}$ gas in this phase have to be determined and included in the mass balance.

To prevent depletion of $\mathrm{O}_{2}$ which can occur in prolonged experiments, the concepts of flow-through respirometry ${ }^{20}$ or intermittent-flow respirometry ${ }^{38}$ can be adapted. Compared with static immersion conditions, a flow cell setup brings new possibilities to study corrosion processes. On the one hand, a flowing electrolyte enables keeping the exposure conditions constant that would be subject to change in a closed system. There, ongoing corrosion can lead to changes in the electrolyte composition like the depletion of dissolved ions or $\mathrm{O}_{2}$, changes in the bulk $\mathrm{pH}$ of the electrolyte, or accumulation of dissolved metal ions. On the other hand, a respirometric flow cell can be used to change the exposure conditions while providing real-time data of the effects on the corrosion rate. Particularly, the electrolyte composition can be changed with respect to e.g. chloride concentration. Another application is to study the effect of the addition of different concentrations of inhibitors, or to elucidate the role of amino acids or other organic molecules present in electrolytes that are commonly used to test biodegradable metals in vitro. In this context it is also possible to realize a change of the temperature of the experiment to values that will be present in the human body. In addition, also the effect of the flow rate on the corrosion rate can be of interest for biodegradable cardiovascular stents or other applications.

Microbial background respiration, i.e. the consumption of dissolved $\mathrm{O}_{2}$ that is not related to the studied corrosion process has to be avoided or determined by experiments without a sample. This aspect can be critical if solutions are studied that contain nutrients for microorganisms. Apart from cleaning and disinfection of the setup, sterilization of the solution or frequent exchange of the solution can help to control interference of background respiration. Other important factors are the construction material of the respirometer and its surface area to volume ratio. ${ }^{39}$ The biofilm formation is also dependent on the temperature $\mathrm{u}^{40}$ and $\mathrm{pH}^{41}$ of the solution.

Electrolytes that contain oxidants other than $\mathrm{O}_{2}$ or water, e.g. nitrate, cannot be studied with the presented setups and would require additional sensors to be analyzed with the respirometric method. Precorroded $\mathrm{Fe}$ samples were shown to reduce $\mathrm{Fe}^{3+}$ ions in the rust scale as a cathodic process parallel to ORR under atmospheric corrosion conditions. ${ }^{42}$ This implies that data generated with respirometric $\mathrm{O}_{2}$ consumption measurements on pre-corroded Fe initially after immersion should be treated with caution. As the amount of reducible $\mathrm{Fe}^{3+}$ in the corrosion products is limited, a steady state ORR rate should be established at some point. Additionally, the evolution or consumption of other gases not related to corrosion has to be excluded. For example, this could be the case for electrolytes supersaturated with $\mathrm{HCO}_{3}{ }^{-}$that can liberate $\mathrm{CO}_{2}$ gas.

Volumetric techniques.-Monitoring HER rates volumetrically is well established to study, e.g. $\mathrm{Mg}$ or $\mathrm{Al}$ corrosion. ${ }^{14,15,32}$ The volume of $\mathrm{H}_{2}$ gas evolved from the sample can be measured for example with a setup containing a funnel inserted in an inverted burette, initially filled with electrolyte (Fig. 2a). Gradually, the electrolyte gets displaced by the collected $\mathrm{H}_{2}$ gas and the volume can be obtained from the burette reading. A more sensitive gravimetric technique (Fig. 2b) was first presented by Curioni ${ }^{14}$ and further developed by Fajardo and Frankel. ${ }^{43}$ In this setup, a collection container is submerged together with the sample and both are connected to a balance. A change of the gas volume under the collection container causes a change in buoyancy that can be measured as a weight change with the balance. The benefit of the gravimetric method over the burette setup is that it provides a higher sensitivity, better time resolution and improved collection efficiency, as also $\mathrm{H}_{2}$ bubbles that stick to the sample are registered. ${ }^{43}$

One possible source of error with these open systems is a loss of $\mathrm{H}_{2}$ gas by dissolution into the electrolyte and to the ambient air that can lead to an underestimation of the amount of detected $\mathrm{H}_{2}$. Presaturation of the electrolyte could resolve this issue for short-term experiments but is another step that complicates the experiment. Moreover, pre-saturation by bubbling with pure $\mathrm{H}_{2}$ gas leads to the unintended displacement of dissolved $\mathrm{O}_{2}$, while pre-saturation by electrolyzing chloride containing solutions can lead to $\mathrm{pH}$ changes and the generation of reactive chlorine species at the anode which could influence the corrosion mechanism. ${ }^{44}$ Figure $2 \mathrm{c}$ shows the schematic of a gravimetric setup with reduced volume of electrolyte that was designed in this study to minimize the dissolution of $\mathrm{H}_{2}$ into the electrolyte. An air headspace separates the electrolyte in contact with the sample from the electrolyte that is necessary for complete submersion of the collection assembly. That way, the dissolution of $\mathrm{H}_{2}$ is limited to a high extent to the small volume of the immersion electrolyte. As an alternative to the air headspace, the immersion volume can be confined with a flexible rubber barrier (Fig. 2d) that must be able to adapt to volume changes without the build-up of a pressure.

The gravimetric setup can be used also to monitor samples that show only $\mathrm{O}_{2}$ consumption and negligible HER rate. As the dissolved $\mathrm{O}_{2}$ cannot be detected with the buoyancy method, an air headspace is required and the consumption of $\mathrm{O}_{2}$ gas from that headspace is monitored by the volume reduction gravimetrically. Because of the gas exchange at the liquid-gas interface, the consumption of dissolved $\mathrm{O}_{2}$ by the corroding sample leads to a depletion of $\mathrm{O}_{2}$ also in the gas phase that can be readily detected with the balance. The addition of a flexible rubber barrier is necessary for limiting the exchange of dissolved $\mathrm{O}_{2}$ with the surrounding solution (Fig. 2d). Monitoring both HER and ORR simultaneously with the volumetric setup is feasible with the addition of an optical $\mathrm{O}_{2}$ sensor that determines the partial pressure of $\mathrm{O}_{2}$ in the headspace non-invasively through the vessel wall without touching the collection container.

The volume of the collection assembly and the volume of air initially present at the beginning of the experiment can be determined from buoyancy considerations as described in a previous paper. ${ }^{45}$ To correct for changes in the gas volume that are solely caused by changes in temperature and atmospheric pressure, these quantities have to be logged throughout the experiment. The correction is described in more detail in earlier work. ${ }^{45}$ Another influence on the measurement is the density of the solution that depends on the amount of dissolved salts and temperature. According to Archimedes' principle, the change in the volume of the gas $V_{\text {gas }}(t)$ is directly related to the measured change in the apparent weight of the collection container $W_{\text {balance }}(t)$ by:

$$
V_{\text {gas }}(t)=-\frac{W_{\text {balance }}(t)}{g \rho_{\text {solution }}(t)}
$$

where $\rho_{\text {solution }}(t)$ is the density of the solution and $\mathrm{g}$ is gravitational acceleration. The gas volume increases for HER and decreases for ORR and hence, the apparent weight will decrease or increase, respectively. The pressure of the gas is given mainly by the actual atmospheric pressure $p_{\text {atm }}(t)$. The hydrostatic pressure of the water column may be neglected for small immersion depths and dilute solutions. ${ }^{43}$ Water vapor occupies part of the volume, so its partial pressure $p_{\mathrm{H}_{2} \mathrm{O}}(t)$ has to be subtracted from the atmospheric pressure. With ideal gas law, and taking into account the above influences, the change in the amount of substance of gas under the collection container can be calculated. ${ }^{45}$

$$
\Delta n=\frac{\left(p_{\text {atm }}(t)-p_{\mathrm{H}_{2} \mathrm{O}}(t)\right) \Delta V_{\text {gas }}(t)}{R T(t)}
$$

$\Delta n(t)$ will increase in the case of HER and decrease for ORR as a cathodic reaction. For mixed HER and ORR the $\mathrm{O}_{2}$ partial pressure changes $\Delta p_{o_{2}}(t)$ can be determined from parallel optical $\mathrm{O}_{2}$ measurements in order to determine the amount of consumed $\mathrm{O}_{2}$. 


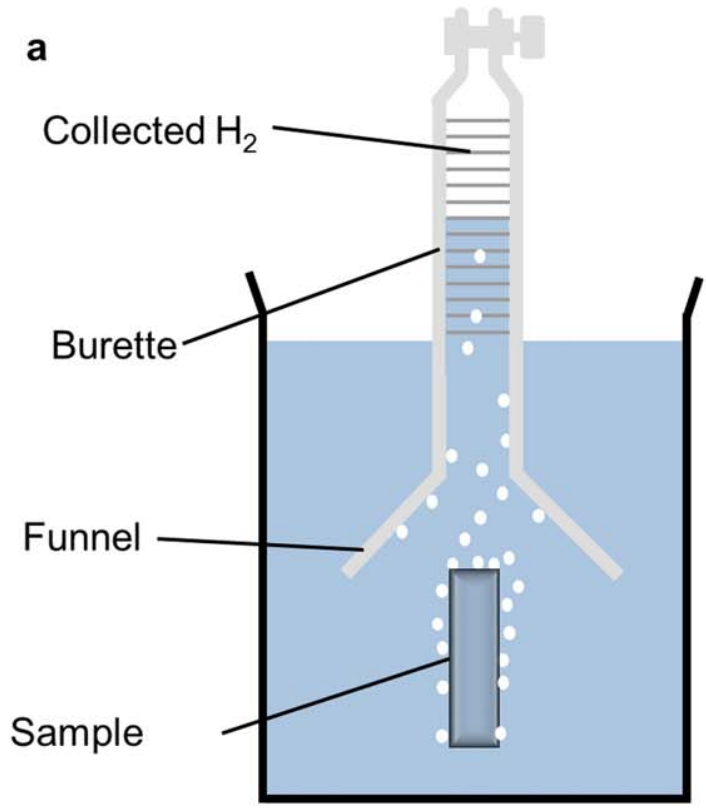

b

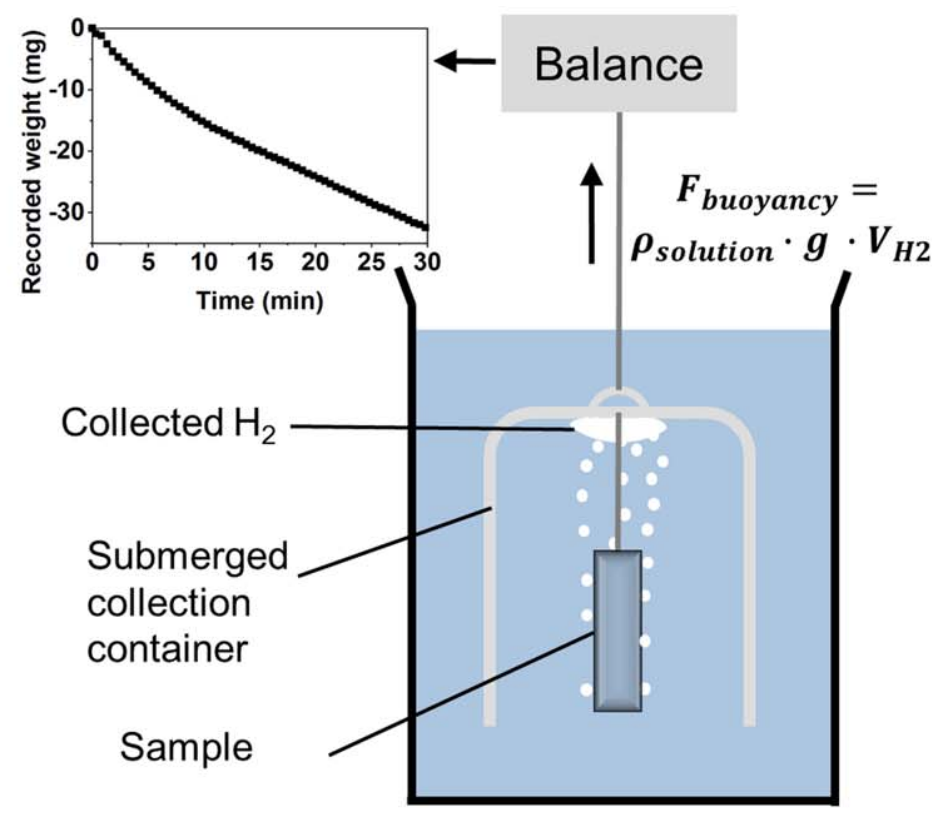

d

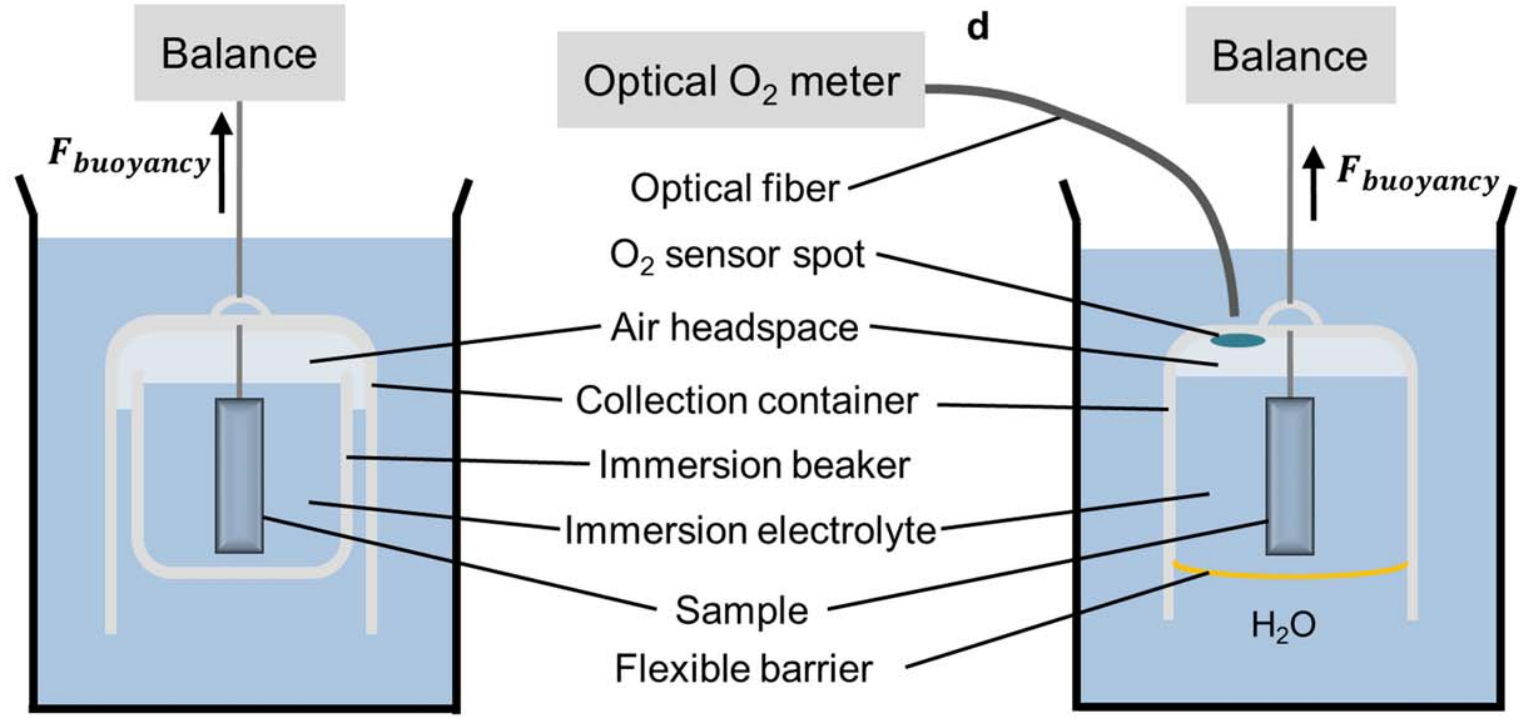

Figure 2. Schematic representation of immersion respirometric setups: (a) inverted burette volumetric setup, (b) experimental setup for gravimetric $\mathrm{H}_{2}$ collection, (c) volume reduced gravimetric setup for volumetric respirometric measurements and (d) flexible rubber barrier respirometric setup to separate the immersion electrolyte from the surrounding solution. With an optical $\mathrm{O}_{2}$ sensor simultaneous monitoring of HER and ORR is possible with setup (d).

Changes in the amount of substance are converted to cathodic charge with Faraday's law (Eq. 8), where $\mathrm{z}$ is the number of exchanged electrons and $\mathrm{F}$ is the Faraday constant. Taking the derivative of the charge vs time curve results in the HER or ORR current.

$$
\Delta Q_{H E R / O R R}(t)=\Delta n_{H_{2} / O_{2}}(t) \Delta z_{H E R / O R R} \cdot F
$$

Manometric technique.-A manometric respirometric approach to monitor HER and ORR rates simultaneously in immersion conditions is shown in Fig. 3a. The sample is immersed in a closed chamber with a fixed volume with a gas phase above the liquid phase. A combined sensor for pressure, temperature and relative humidity $(\mathrm{RH})$ is placed in the gas headspace above the solution to measure HER rates. The amount of $\mathrm{O}_{2}$ in the gas phase can be monitored with an optical $\mathrm{O}_{2}$ sensor. The amount of $\mathrm{O}_{2}$ in the liquid phase can be either measured with a second optical $\mathrm{O}_{2}$ sensor or it can be assumed that both phases are in equilibrium. Then, the concentration of $\mathrm{O}_{2}$ dissolved in the liquid phase can be calculated from the partial pressure in the gas phase. The solubility of $\mathrm{O}_{2}$ in the electrolyte is a function of $\mathrm{O}_{2}$ partial pressure, salinity and temperature and can be estimated with empirical equations. ${ }^{46}$ The validity of the equilibrium assumption should be carefully checked by determining the concentration with a second $\mathrm{O}_{2}$ sensor. ${ }^{26}$ The rate of gas exchange between the gas and liquid phase is determined by the area dimension of the interface which is given by the geometric dimension of the chamber. One of the most important factors affecting the exchange velocity of a sparingly soluble gas such as $\mathrm{O}_{2}$ is the degree of mixing of the liquid phase. ${ }^{47-49}$ Apart from acceleration of gas exchange, mixing is also important to ensure that the measured concentration of $\mathrm{O}_{2}$ corresponds to the mean concentration value of the liquid phase. ${ }^{38,39}$ Gradients in $\mathrm{O}_{2}$ concentration would otherwise lead to incorrect calculations of $\mathrm{O}_{2}$ consumption rates.

To determine the amount of consumed $\mathrm{O}_{2}$ molecules $\Delta n_{O_{2}}(t)$, besides partial pressure changes in the gas phase $\Delta p_{O_{2}}^{\text {gas }}(t)$, changes in the concentration of $\mathrm{O}_{2}$ dissolved in the liquid phase $\Delta C_{O_{2}}^{l i q}$ have 


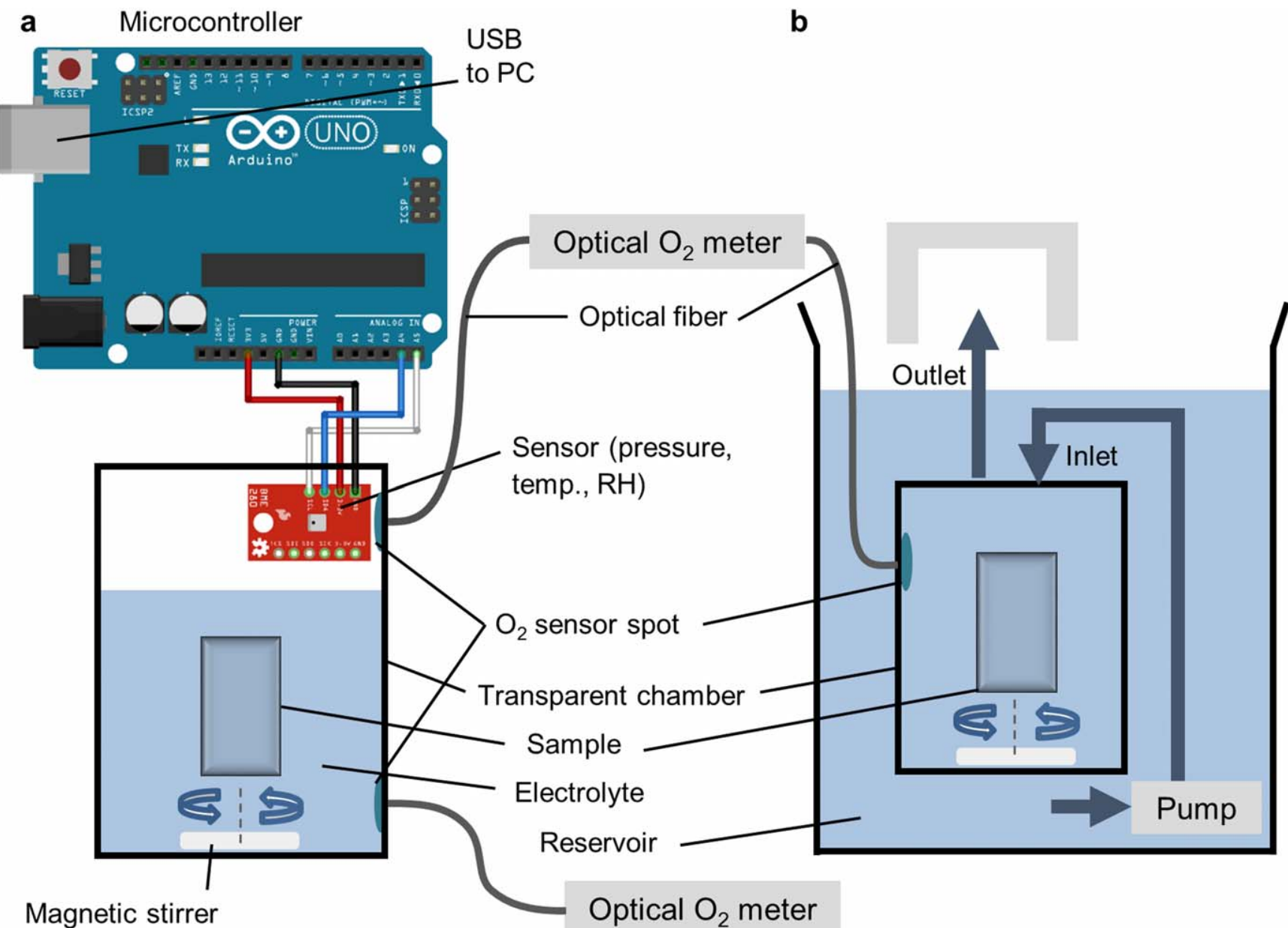

Figure 3. Schematic representation of immersion experimental setups: (a) simultaneous monitoring of HER and ORR rates with a static, manometric respirometric method and (b) monitoring of ORR rates with an intermittent-flow respirometric method.

to be considered.

$$
\begin{aligned}
\Delta n_{O_{2}}(t) & =\Delta n_{O_{2}}^{\text {gas }}(t)+\Delta n_{O_{2}}^{\text {liq }}(t)=\frac{\Delta p_{O 2}^{\text {gas }}(t) \cdot V_{\text {gas }}}{R \cdot T(t)} \\
& +\Delta C_{O_{2}}^{\text {liq }} \cdot V_{\text {liq }}
\end{aligned}
$$

with $V_{\text {gas }}$ and $V_{\text {liq }}$ being the volume of the gas phase and liquid phase, respectively, and $\mathrm{R}$ is the the ideal gas constant.

The rate of $\mathrm{H}_{2}$ evolution is determined by the pressure increase inside the closed chamber. As shown in the previous part of the paper, the HER charge can be calculated from the change in the total pressure inside the chamber $\Delta p_{\text {tot }}(t)$ with a combination of ideal gas law (Eq. 10) and Faraday's law (Eq. 8). Therefore, the changes in $\mathrm{O}_{2}$ partial pressure $\Delta p_{O 2}^{\text {gas }}(t)$, water vapor pressure $\Delta p_{\mathrm{H}_{2} \mathrm{O}}(t)$ and temperature of the gas phase $T(t)$ have to be also taken into account. The temperature of the experiment should be maintained constant or measured at the position of the gas volume. Accurate temperature recording is a prerequisite for both the calculation of the amount of gas molecules, as well as for the internal automatic temperature compensation of the optical $\mathrm{O}_{2}$ sensor.

$$
\Delta n_{H_{2}}(t)=\frac{\left(\Delta p_{t o t}(t)-\Delta p_{O_{2}}^{g a s}(t)-\Delta p_{H_{2} O}(t)\right) \cdot V_{g a s}}{R \cdot T(t)}
$$

Water is virtually incompressible compared to a gas. Thus, a smaller gas phase volume inside the chamber leads to faster pressure changes and to an improved detection limit.
The evolution of $\mathrm{RH}$ inside the gas volume can be measured in situ by the RH sensor with the manometric setup. This allows calculation of the water vapor pressure $\Delta p_{\mathrm{H}_{2} \mathrm{O}}(t)$ from the saturation vapor pressure $p_{\mathrm{H}_{2} \mathrm{O}}^{\mathrm{sat}}$ which is a function of temperature (Eq. 11).

$$
p_{H 2 O}(t)=R H(t) p_{H_{2} O}^{s a t}
$$

The amount of dissolved $\mathrm{H}_{2}$ can be estimated with Henry's law:

$$
C_{H 2}^{\text {diss }}=H \cdot p_{H_{2}}^{\text {gas }}
$$

Here, $\mathrm{H}$ is Henry's law solubility constant, $\mathrm{C}_{\mathrm{H}_{2}}^{\text {diss }}$ is the concentration of $\mathrm{H}_{2}$ in the aqueous phase, and $p_{\mathrm{H} 2}^{\text {gas }}$ is the partial pressure of $\mathrm{H}_{2}$ in the gas phase under equilibrium conditions.

A conservative estimation for this calculation is to use the actual $\mathrm{H}_{2}$ partial pressure in the gas phase that was provided by the pressure increase. Regarding the $\mathrm{H}_{2}$ distribution between gas and liquid phases, significant supersaturation with respect to Henry's law was observed which was attributed to a major resistance to $\mathrm{H}_{2}$ transfer from the liquid phase to the gas phase. ${ }^{50}$ An upper boundary for the amount of dissolved $\mathrm{H}_{2}$ is given assuming a partial pressure of $\mathrm{H}_{2}$ that is equal to the total pressure inside the chamber. This can be rationalized by the fact that the $\mathrm{H}_{2}$ bubbles evolved from the sample surface are initially pure $\mathrm{H}_{2}$ before they rise up to the gas headspace. This means that the solution around these bubbles equilibrates with $\mathrm{H}_{2}$ under a partial pressure close to the total pressure. The true amount of dissolved $\mathrm{H}_{2}$ will be in between these 
two scenarios and probably closer to the lower limit. Taking into account the concentration of $\mathrm{O}_{2}$ and $\mathrm{H}_{2}$ in both phases allows for a full mass balance. The actual rates of both HER and ORR can be obtained from the slope of the respective charge curves. Thus, the total respirometric corrosion rate is the sum of both HER and ORR rates.

Intermittent-flow ORR Monitoring.-Corrosion systems that corrode mainly with ORR and not with visible $\mathrm{H}_{2}$ gas evolution can be monitored by an $\mathrm{O}_{2}$ sensor approach as shown in Fig. 3b. The consumption of $\mathrm{O}_{2}$ by a sample that is immersed in a completely filled chamber with a fixed volume of electrolyte is determined, e.g. with an optical $\mathrm{O}_{2}$ sensor. For very low corrosion rates it might be sufficient to use static exposure in a completely closed chamber. However, for higher corrosion rates or prolonged exposure, the level of $\mathrm{O}_{2}$ in the solution needs to be restored periodically. In intermittent-flow respirometry this is achieved by periodically flushing the chamber with fresh, air saturated solution. The $\mathrm{O}_{2}$ consumption rate can be determined from the slopes of the $\mathrm{O}_{2}$ concentration decrease during each measurement phase of the sawtooth curve together with the volume of electrolyte in the chamber. The fundamental principles that need to be considered when designing and carrying out automated intermittent-flow respirometry measurements are accurately described by Svendsen et al. ${ }^{38}$ For this kind of experiment the chamber does not need to be hermetically closed. Rather, the chamber has two ports for an inlet and outlet of electrolyte flow. One-way flow valves can be used to avoid the exchange of $\mathrm{O}_{2}$ with the surrounding reservoir bath. The same function can be provided by inlet tubing of sufficient length and by designing the outlet as an overflow that is positioned above the liquid level of the electrolyte reservoir bath. ${ }^{27}$ The flush pump can be triggered automatically with a given time interval or when a defined critical $\mathrm{O}_{2}$ concentration is reached in the chamber. Again, mixing of the solution is important in order to avoid concentration gradients. Mixing can be achieved by stirring the solution or by using a pump inside the chamber, or in a separate recirculation loop. ${ }^{38}$ In the case of a separate recirculation loop, the total liquid volume comprises the chamber volume plus the volume in the recirculation loop. What should be kept in mind is that the degree of agitation also influences the corrosion rate. Stirring the solution increases the rate of diffusional mass transport of $\mathrm{O}_{2}$ by decreasing the thickness of the Nernst diffusion layer.

Gas bubbles inside the chamber should be avoided as they provide a possible source or sink for $\mathrm{O}_{2}$. Therefore, the outlet should be positioned on the topmost part of the chamber and designed in a way to facilitate the removal of gas during flush phases. If the fountain of water from the overflow is not sufficient to hold the $\mathrm{O}_{2}$ concentration level of the reservoir close to saturation, the reservoir bath can be aerated with an air pump. Possible background $\mathrm{O}_{2}$ consumption by microbial activity can be measured in a parallel chamber without sample that is periodically flushed with the same solution as the sample chamber.

Continuous flow-through techniques.-Another approach is to use a continuous flow of electrolyte that passes the corroding sample in a respirometric chamber (Fig. 4). The concentration of dissolved $\mathrm{O}_{2}$ in the electrolyte is measured in the incurrent $\left(C_{O 2}^{i n}\right)$ and excurrent $\left(C_{O 2}^{e x}\right)$ stream. The rate of $\mathrm{O}_{2}$ consumption can be calculated from the concentration difference together with the flow rate $\dot{V}$ and converted to a current with Faraday's law:

$$
I_{O R R}=\left(C_{O 2}^{i n}-C_{O 2}^{e x}\right) \cdot \dot{V} \cdot z_{O R R} \cdot F
$$

The flow rate is an important parameter that should be accurately controlled or measured. Sensor drift can be an issue that impairs oxygen readings, especially if two sensors are used. This sensorbased error can be reduced by utilizing a valve system that allows the same probe to sample both streams.

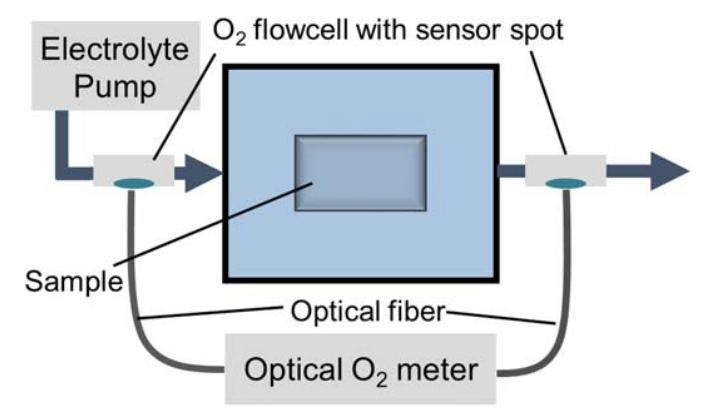

Figure 4. Flow-through respirometric setup to monitor ORR rates based on the measurement of $\mathrm{O}_{2}$ concentration in a stream of electrolyte before and after passing a corroding sample in a chamber.

Another issue to be considered for flow-through measurements is that changes in the corrosion rate on a short time-scale are not instantly reflected in the response due to a lag in time and mixing problems. $^{21,38}$ These washout characteristics depend on the ratio of flow rate to chamber volume of the respirometry system and can usually be satisfactorily corrected mathematically. ${ }^{21,51}$ Ignoring the washout characteristics of the system may result in misinterpretation of the obtained results. ${ }^{20}$ Decreasing the flow rate would increase the signal of the excurrent $\mathrm{O}_{2}$ sensor which increases the sensitivity of the measurement. However, it takes more time until the measurement responds to changes in $\mathrm{O}_{2}$ consumption rate due to washout. ${ }^{20}$

Systems that corrode mainly with HER as a cathodic reaction can be monitored in a flow-through cell with a gravimetric $\mathrm{H}_{2}$ collection experimental setup similar to the one presented by Han et al. ${ }^{52}$ The $\mathrm{H}_{2}$ gas bubbles evolved from the corroding sample in a respirometric chamber are transported with the flow of electrolyte. The flow outlet is directed under a submerged collection container that detects the amount of $\mathrm{H}_{2}$ gravimetrically with a balance. The collected $\mathrm{H}_{2}$ gas exerts a buoyant force that can be monitored as a change in the apparent weight of the collection container. Care must be taken that bubbles are not retained in bends or junctions. Because the $\mathrm{H}_{2}$ exits the tubing discontinuously as discrete bubbles, the weight curve shows a step-like course. What must be kept in mind is that $\mathrm{H}_{2}$ gas is soluble in water. Therefore, depending on the flow rate, much of the generated $\mathrm{H}_{2}$ is dissolved and hence not detected with the gravimetric measurement.

Combining both flow-through approaches to monitor HER and ORR simultaneously is not advisable because the evolved $\mathrm{H}_{2}$ gas takes up $\mathrm{O}_{2}$ from the solution. Even if no $\mathrm{O}_{2}$ is consumed by corrosion the second $\mathrm{O}_{2}$ sensor will detect a lower amount of dissolved $\mathrm{O}_{2}$ in the excurrent stream, thus, suggesting ORR activity that is not real.

\section{Experimental}

Materials, sample preparation and electrolytes.-Die cast high purity Mg alloy AM50 and AZ91 plates with a thickness of $2 \mathrm{~mm}$ were supplied by DGS Druckgusssysteme AG, Germany. High purity AZ31 sheet material was obtained from MgF Magnesium Flachprodukte $\mathrm{GmbH}$, Germany. $\mathrm{Zn}$ foil $(0.125 \mathrm{~mm}$ thickness, purity $99.99 \%$, typical analysis ppm: Fe 19, Cd 19, $\mathrm{Pb}<40$, $\mathrm{Cu}<50$ ) was obtained from Advent Research Materials Ltd., England. Specimens were prepared by cutting or sawing and a hole was drilled to attach a nylon string. The sample surface was prepared by grinding to 1200 grit with $\mathrm{SiC}$ paper and cleaning with ethanol.

The composition of the immersion electrolytes can be found in Table I. Dulbecco's Modified Eagle's Medium (DMEM) is a cell culture medium that is frequently used to assess the corrosion behavior of biodegradable metals in vitro. Besides a $0.1 \mathrm{M} \mathrm{NaCl}$ solution, tests were also carried out in inorganic DMEM without $\mathrm{NaHCO}_{3}$. This solution was prepared by adding only the inorganic salts of the DMEM cell culture medium and leaving out the organic constituents. Additionally, DMEM without $\mathrm{NaHCO}_{3}$, that contains 
Table I. Electrolyte composition in $\mathrm{mg} \mathrm{l}^{-1}$. A detailed concentration overview of the substances contained in the used DMEM electrolyte can be found in the literature. ${ }^{53}$

\begin{tabular}{|c|c|c|c|c|c|c|c|c|}
\hline Electrolyte & $\mathrm{NaCl}$ & $\mathrm{KCl}$ & $\mathrm{MgSO}_{4} \cdot 7 \mathrm{H}_{2} \mathrm{O}$ & $\mathrm{CaCl}_{2}$ & $\mathrm{NaH}_{2} \mathrm{PO}_{4} \cdot \mathrm{H}_{2} \mathrm{O}$ & $\mathrm{Fe}\left(\mathrm{NO}_{3}\right)_{3} \bullet 9 \mathrm{H}_{2} \mathrm{O}$ & Amino acids, vitamins, phenol red & Glucose \\
\hline $0.1 \mathrm{M} \mathrm{NaCl}$ & 5844 & 0 & 0 & 0 & 0 & 0 & no & 0 \\
\hline Inorganic DMEM w/o $\mathrm{NaHCO}_{3}$ & 6400 & 400 & 200 & 200 & 125 & 0 & no & 0 \\
\hline DMEM w/o $\mathrm{NaHCO}_{3}$ & 6400 & 400 & 200 & 200 & 125 & 0.1 & yes & 1000 \\
\hline
\end{tabular}

DMEM w/o $\mathrm{NaHCO}_{3}$

125

0.1 
all organic constituents like amino acids, vitamins and glucose, was prepared from powder medium (T 041, Biochrom) by adding highpurity water without sterile filtration. DMEM media are usually buffered with the bicarbonate/ $\mathrm{CO}_{2}$ buffer system. In this work, $\mathrm{NaHCO}_{3}$ was not added because of possible interference of $\mathrm{CO}_{2}$ gas evolution with the respirometric method. The initial $\mathrm{pH}$ of the three solutions was not adjusted to the physiological value of 7.4 but was ca. 5.8 for $0.1 \mathrm{M} \mathrm{NaCl}$ and 5.2 for the DMEM electrolytes.

Gravimetric setups for volumetric corrosion rate monitoring.To measure changes in the gas volume gravimetrically with the configuration shown in Fig. 2b, the sample was attached to the hook of a collection container fully made of glass. A thin, monofilament fiber was used to attach the beaker to the balance in order to measure changes in the buoyant force exerted by the changes in gas volume. For more accuracy, it is important to fully submerge the collection setup. Otherwise, possible evaporation of electrolyte would lead to partial emergence of the setup which would cause the measured buoyant force to decrease. A syringe with a bent plastic tube was used to initially remove the air under the collection container. The temperature and atmospheric pressure were logged during the experiments in order to correct for the influences on the gas volume.

The volume-reduced gravimetric setup as in Fig. 2c was constructed from a smaller glass beaker containing the immersed sample with a defined amount of corrosive electrolyte. This beaker was covered by a second, inverted beaker that collects the evolved $\mathrm{H}_{2}$ gas. While both glass beakers were connected mechanically, a small air headspace separated the immersion electrolyte from the outer electrolyte where the whole assembly was submerged in. A minimum and maximum amount of dissolved $\mathrm{H}_{2}$ was calculated using the actual $\mathrm{H}_{2}$ partial pressure in the gas phase and the total pressure of the gas phase, respectively, using Henry's law and a Henry constant of $7.7 \cdot 10^{-6} \mathrm{~mol} /\left(\mathrm{m}^{3} \mathrm{~Pa}\right) .^{54}$

To demonstrate real-time HER monitoring with the different gravimetric setups, Mg alloys AZ31, AM50 and AZ91 were exposed in $0.1 \mathrm{M} \mathrm{NaCl}$ for $48 \mathrm{~h}$. The experiments were repeated 2 to 3 times for each alloy and setup. After gravimetric measurements, the corroded sample was removed, and mass gain and mass loss measurements were carried out by cleaning with $200 \mathrm{~g} \mathrm{l}^{-1} \mathrm{CrO}_{3}$ solution. After the experiment, $\mathrm{HNO}_{3}$ was added to the immersion solution to dissolve precipitated corrosion products and the solution was filled up with high purity water $(18.2 \mathrm{M} \Omega \mathrm{cm})$ to make $1000 \mathrm{ml}$. After further dilution the solution was analyzed with IC (Metrohm 883 Basic IC plus) to determine the concentration of $\mathrm{Mg}^{2+}$ ions. The IC device was equipped with a Metrosep C4 - 150/4.0 separation column and the eluent was water with $0.7 \mathrm{mmol}^{-1}$ dipicolinic acid and $1,7 \mathrm{mmol}^{-1} \mathrm{HNO}_{3}$. The amount of $\mathrm{Mg}^{2+}$ that remained on the sample was estimated from mass gain and mass loss values, assuming $\mathrm{Mg}(\mathrm{OH})_{2}$ as the dominant corrosion product.

Static setup for manometric corrosion rate monitoring.-The static setup for simultaneous HER and ORR monitoring is similar to the manometric setup presented in Part I of the paper series. In this setup, the sample was immersed in an electrolyte inside a gas-tight, transparent chamber. A DURAN ${ }^{\circledR}$ laboratory glass bottle was used as a chamber and it was sealed with a DURAN ${ }^{\circledR}$ bromobutyl rubber stopper. In this work, the chamber was submerged in a water bath that was not temperature controlled in order to stabilize the temperature. A Bosch BME 280 combined sensor for absolute pressure, temperature and relative humidity was placed in the air headspace of the vessel. The electronic components of the sensor breakout board were protected from condensation by a coating with a two-component epoxy and additionally wrapped with Teflon tape. The sensor was connected via a gastight feedthrough to an Arduino Uno microcontroller. The $\mathrm{O}_{2}$ partial pressure was measured both in the liquid phase and in the gas phase with two Piccolo2-OEM optical $\mathrm{O}_{2}$ meters with contactless sensor spots (PyroScience, Germany) that were glued to the inner wall of the transparent chamber. In some experiments, a LuminOx LOX-02-S optical $\mathrm{O}_{2}$ sensor (SST Sensing, UK) was used to measure gas phase $\mathrm{O}_{2}$ partial pressure and total pressure. This sensor is only applicable for gas phase $\mathrm{O}_{2}$ monitoring but showed a comparable performance to the PyroScience sensor. Since no RH measurement is possible with the Luminox sensor, the average RH-time profile of several comparable BME 280 measurements was used in this case. Mixing of the liquid phase was provided by a magnetic stirrer at $200 \mathrm{rpm}$. The Arduino microcontroller read out both the BME280 sensor and the optical $\mathrm{O}_{2}$ sensors and the results were returned in a comma separated format. The microcontroller was connected to a computer and the CoolTerm terminal software was used to capture the data to a text file. In addition, a live plotter was developed that enables one to analyze and visualize the data in a real-time graph both on the measurement computer and remotely from anywhere over the internet. The volume of the chamber was determined by weighing the amount of water necessary to completely fill the chamber. The volume of the immersion electrolyte was also determined by weighing. The volume of the gas phase was calculated from the chamber volume minus the volumes of liquid phase, sample, sensor and stir bar. Imaging of the surface during exposure was carried out with a USB microscope PCE-MM 400 in order to construct a time-lapse video of the corrosion progress.

Intermittent-flow ORR monitoring setup.-A PyroScience optical $\mathrm{O}_{2}$ sensor was used to monitor the concentration of dissolved $\mathrm{O}_{2}$ in a chamber completely filled with electrolyte, i.e. without gas headspace. To restore the level of $\mathrm{O}_{2}$, the chamber was periodically flushed by pumping fresh aerated solution from an outer electrolyte reservoir. The electrolyte in the reservoir bath was air saturated at the beginning of the experiment. The solution exiting the chamber through an overflow was in contact with air before flowing back to the electrolyte reservoir and was thereby reaerated. The flush pump was triggered automatically by an Arduino microcontroller via a relay module that switches power on or off. A flush phase of $30 \mathrm{~s}$ every 30 min was used in most experiments.

The $\mathrm{O}_{2}$ consumption rate was extracted from the slopes of the sawtooth $\mathrm{O}_{2}$ concentration curves. As no rate could be determined during the flush phase, it was assumed that the corrosion rate from the previous measurement phase persisted also during this period. The cumulative amount of consumed $\mathrm{O}_{2}$ was obtained by integrating the rate curves. The cumulative amount of consumed $\mathrm{O}_{2}$ was compared with the amount of corroded $\mathrm{Zn}$ obtained from mass loss in order to calculate the number of exchanged electrons $\mathrm{z}_{\mathrm{ORR}}$ in the ORR.

To test for background respiration, the $\mathrm{O}_{2}$ consumption was measured after the experiments when the sample was removed. In DMEM the background $\mathrm{O}_{2}$ consumption was directly monitored throughout the experiment with a second chamber without sample. Both chambers were flushed by the same pump using a junction and the flush time was increased to $2 \mathrm{~min}$.

Continuous flow-through ORR setup.-An ORR continuous flow-through setup was constructed using two PyroScience $\mathrm{O}_{2}$ flow cells with integrated contactless optical $\mathrm{O}_{2}$ sensor spots that were read out by two Piccolo2-OEM optical $\mathrm{O}_{2}$ meters. The sensors were located at the inlet and outlet of a respirometric chamber of approximately $25 \mathrm{ml}$ volume that contained the sample. A peristaltic pump supplied a continuous stream of electrolyte. The flow rate was determined gravimetrically and was found to be $32.6 \mathrm{ml}$ per minute.

Mass loss measurements.-After exposure, to remove the corrosion products, the samples were immersed in a pickling solution ( $\mathrm{Zn:} 250 \mathrm{~g} \mathrm{l}^{-1}$ glycine solution, $\mathrm{Mg}$ alloys: $200 \mathrm{~g} \mathrm{l}^{-1}$ $\mathrm{CrO}_{3}$ ) according to ISO $8407 .^{3}$ The amount of metal loss was determined by weighing the samples before exposure and after removal of the corrosion products with a balance (Mettler Toledo XA205DU). The value was converted to an anodic charge using Faraday's law. 


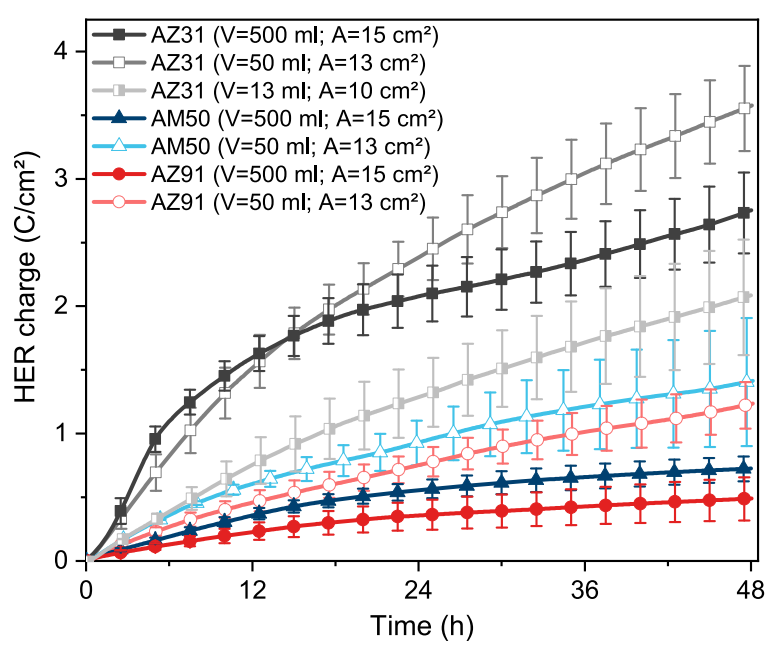

Figure 5. HER charge curves determined from gravimetric $\mathrm{H}_{2}$ collection measurements of different $\mathrm{Mg}$ alloys immersed for $48 \mathrm{~h}$ in different volumes of $0.1 \mathrm{M} \mathrm{NaCl}$ solution. The measurements of replicate samples are normalized to the sample area, averaged and plotted together with the standard deviation. Although the $50 \mathrm{ml}$ samples actually corroded less compared to the $500 \mathrm{ml}$ samples, more $\mathrm{H}_{2}$ was detected because of a reduced influence of $\mathrm{H}_{2}$ dissolution (see Fig. 7).

\section{Results and Discussion}

Gravimetric volumetric experiments.-The influence of temperature and ambient pressure on the baseline of gravimetric experiments was already reported before. After correcting for environmental fluctuations, the gravimetric method exhibits a good reproducibility and is sensitive enough to monitor HER rates in the low $\mu \mathrm{A}$ range. Gravimetric measurements of three different $\mathrm{Mg}$ alloys were carried out with the regular gravimetric setup (Fig. 2b) to monitor HER rates in real-time with the samples being immersed in $500 \mathrm{ml}$ of $0.1 \mathrm{M} \mathrm{NaCl}$. Additional measurements with the volume reduced gravimetric setup depicted in Fig. $2 \mathrm{c}$ were carried out to test the influence of the immersion electrolyte volume to surface area on the corrosion rate and on the amount of dissolved $\mathrm{H}_{2}$.

From the gravimetric results shown in Fig. 5 it can be seen that the corrosion rate decreases with an increase in the amount of $\mathrm{Al}$ in the alloy, with AZ91 samples evolving the lowest amount of $\mathrm{H}_{2}$. A similar trend of decreasing global corrosion rate with increasing $\mathrm{Al}$ content was also observed by Bland et al. ${ }^{55}$ While the microstructure of AZ31 is characterized by $\alpha-\mathrm{Mg}$ with $\mathrm{Al}-\mathrm{Mn}$ intermetallic particles, AM50 and AZ91 contain a $\beta-\mathrm{Mg}_{17} \mathrm{Al}_{12}$ second phase as well as eutectic $\alpha+\beta$. These intermetallic phases in $\mathrm{Mg}$ alloys act as cathodes. Therefore, they may initiate microgalvanic corrosion in the surrounding alpha matrix and lead to higher extent of localized attack. ${ }^{55}$ On the other hand, the $\beta$-phase can act as a barrier for the lateral propagation of filiform corrosion fronts. ${ }^{56}$ While the $\beta$-phase is absent in AZ31, its volume fraction increases from AM50 to AZ91. Another influence that determines the corrosion rate of $\mathrm{Mg}-\mathrm{Al}$ alloys is the $\mathrm{Al}$ content in $\alpha-\mathrm{Mg} .{ }^{57}$ Consequently, the trend of increasing corrosion resistance might be explained by a higher $\mathrm{Al}$ content in the $\alpha$-phase and the increasing barrier effect of the $\beta$-phase.

From the slope of the charge curves the real-time HER rate was calculated as shown in Fig. 6. For AZ31, a strong increase in corrosion rate at the beginning of the $500 \mathrm{ml}$ experiments was observed. Parallel optical imaging of the surface revealed that the increase in HER rate coincides with an increase in the number of active corrosion fronts that propagate across the sample. This behavior is diminished for the lower electrolyte volumes. As with AM50 and AZ91, the corrosion rate of AZ31 in the $50 \mathrm{ml}$ and $13 \mathrm{ml}$ setup shows a decline with immersion time. This is probably due to a faster increase of the solution $\mathrm{pH}$ that facilitates the precipitation of $\mathrm{Mg}(\mathrm{OH})_{2}$ on the sample surface and leads to an increased

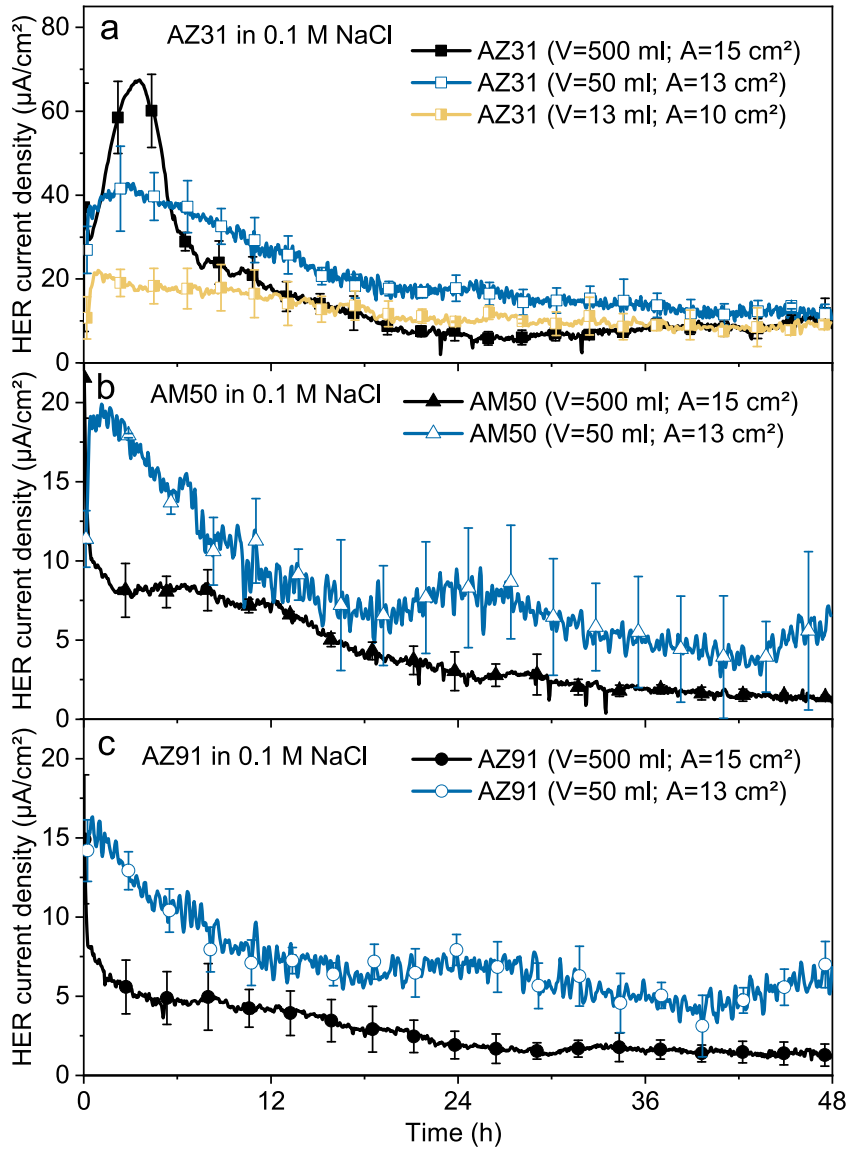

Figure 6. Comparison of real-time HER current density of (a) AZ31, (b) AM50 and (c) AZ91 samples in $0.1 \mathrm{M} \mathrm{NaCl}$ obtained with gravimetric setups of different surface area to electrolyte volume ratios. Average curves of multiple replicate samples are shown together with the standard deviation. Note that the curves show only $\mathrm{H}_{2}$ detected by the balance and are not corrected for dissolved $\mathrm{H}_{2}$. A comparison with mass loss and the estimation of the contribution of $\mathrm{H}_{2}$ dissolved in the liquid phase is given in Fig. 7.

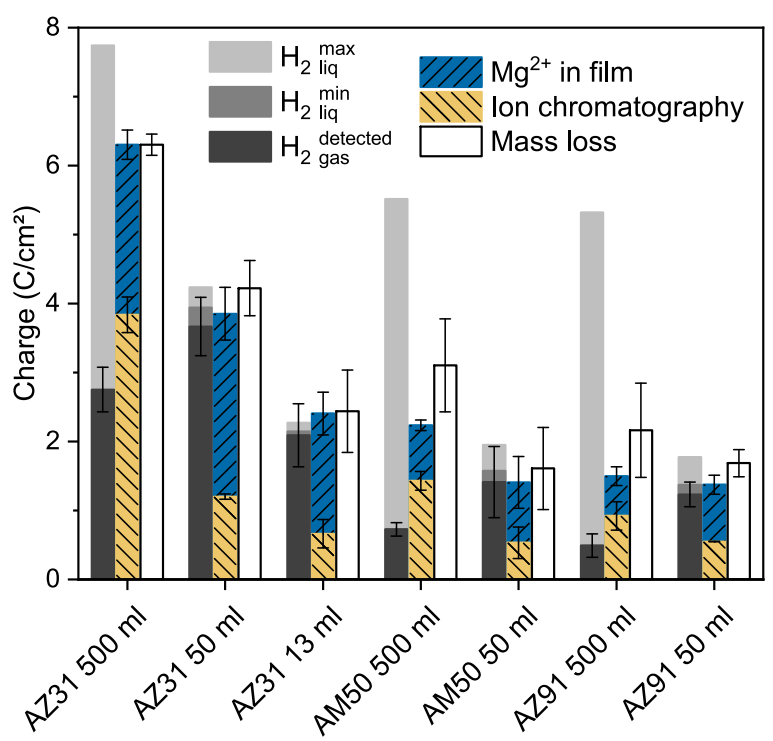

Figure 7. Comparison of the total consumed charge after $48 \mathrm{~h}$ of immersion in $0.1 \mathrm{M} \mathrm{NaCl}$ as determined by gravimetric HER monitoring, solution analysis for dissolved $\mathrm{Mg}^{2+}$ ions with ion chromatography, and mass loss. The amount of $\mathrm{Mg}^{2+}$ in the corrosion film was estimated from mass gain and mass loss. 


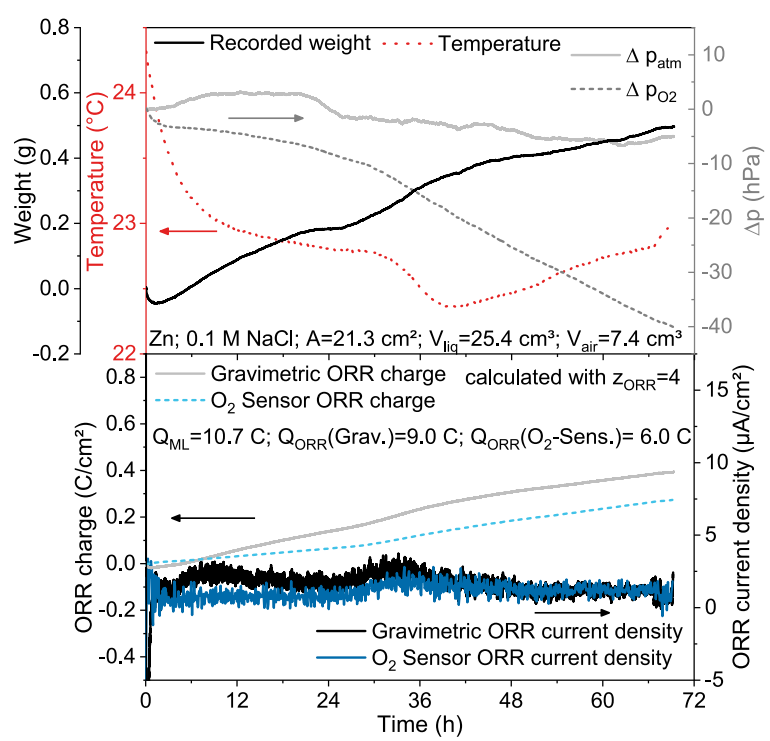

Figure 8. Gravimetric experiment of $\mathrm{Zn}$ corrosion in $0.1 \mathrm{M} \mathrm{NaCl}$ with simultaneous $\mathrm{O}_{2}$ sensor measurement using the setup in Fig. 2 d.

protectiveness against corrosion. Thus, the surface area to electrolyte volume modifies the corrosion mechanism that occurs as well as the total amount of corrosion.

Apart from the activation of corrosion fronts at the beginning of AZ31 corrosion, the HER rates recorded with the $50 \mathrm{ml}$ setup seem to be higher compared to the $500 \mathrm{ml}$ experiments, also for AM50 and AZ91. That this interpretation is slightly misleading can be explained by comparing the total amount of consumed HER charge after $48 \mathrm{~h}$ immersion in $0.1 \mathrm{M} \mathrm{NaCl}$ with the mass loss method (Fig. 7). Comparing the amount of $\mathrm{H}_{2}$ collected with the $500 \mathrm{ml}$ setup with mass loss reveals a substantial discrepancy. For this setup, HER monitoring with AZ31 detected only $44 \%$ of the mass loss charge and less than $25 \%$ in the case of AM50 and AZ91. The discrepancy was attributed to the loss of gaseous $\mathrm{H}_{2}$ by dissolution into the solution. When $\mathrm{H}_{2}$ is dissolved it does not exert a buoyant force anymore and is thus not detected by the gravimetric method. An alternative explanation that could contribute to the discrepancy with mass loss could be that ORR plays a partial role in the corrosion mechanism. Looking at the results with $50 \mathrm{ml}$ and $13 \mathrm{ml}$ electrolyte volume show that the correlation of the amount of detected $\mathrm{H}_{2}$ to the amount of mass loss gets much closer compared to the $500 \mathrm{ml}$ setup. Samples exposed in the volume reduced gravimetric setups show a lower overall amount of corrosion as determined by mass loss for all three $\mathrm{Mg}$ alloys. However, more $\mathrm{H}_{2}$ gas evolution is detected for the $50 \mathrm{ml}$ experiments. This implies that, with the $500 \mathrm{ml}$ setup a big amount of $\mathrm{H}_{2}$ gas is not detected because of dissolution of $\mathrm{H}_{2}$ into the electrolyte.

To further assess the issue of $\mathrm{H}_{2}$ dissolution, two types of dissolved $\mathrm{H}_{2}$ estimations were performed with Henry's law as shown in Fig. 7. The values denoted with $H_{2 l i q}^{\max }$ are HER equivalent charge values that represent the amount of $\mathrm{H}_{2}$ dissolved in the liquid phase that was calculated assuming that the solution is in equilibrium with a gas phase of pure $\mathrm{H}_{2}$ with a pressure equal to the atmospheric pressure. This could be the case for $\mathrm{H}_{2}$ collected in the $500 \mathrm{ml}$ setup where there is no gas headspace. For the volume reduced experiments with a gas headspace, the $H_{2 l i q}^{\min }$ values were calculated assuming that the concentration of dissolved $\mathrm{H}_{2}$ is in equilibrium with the actual partial pressure of $\mathrm{H}_{2}$ in the headspace. Since the gas evolved from the samples is pure $\mathrm{H}_{2}$ at atmospheric pressure before it reaches the headspace, the $H_{2 l i q}^{\max }$ value could be a plausible scenario also for the headspace setup. The true $\mathrm{H}_{2}$ solubility could be ascertained with a sensor for dissolved $\mathrm{H}_{2}$ in future work. The results show that the amount of $\mathrm{H}_{2}$ that could potentially dissolve in $500 \mathrm{ml}$

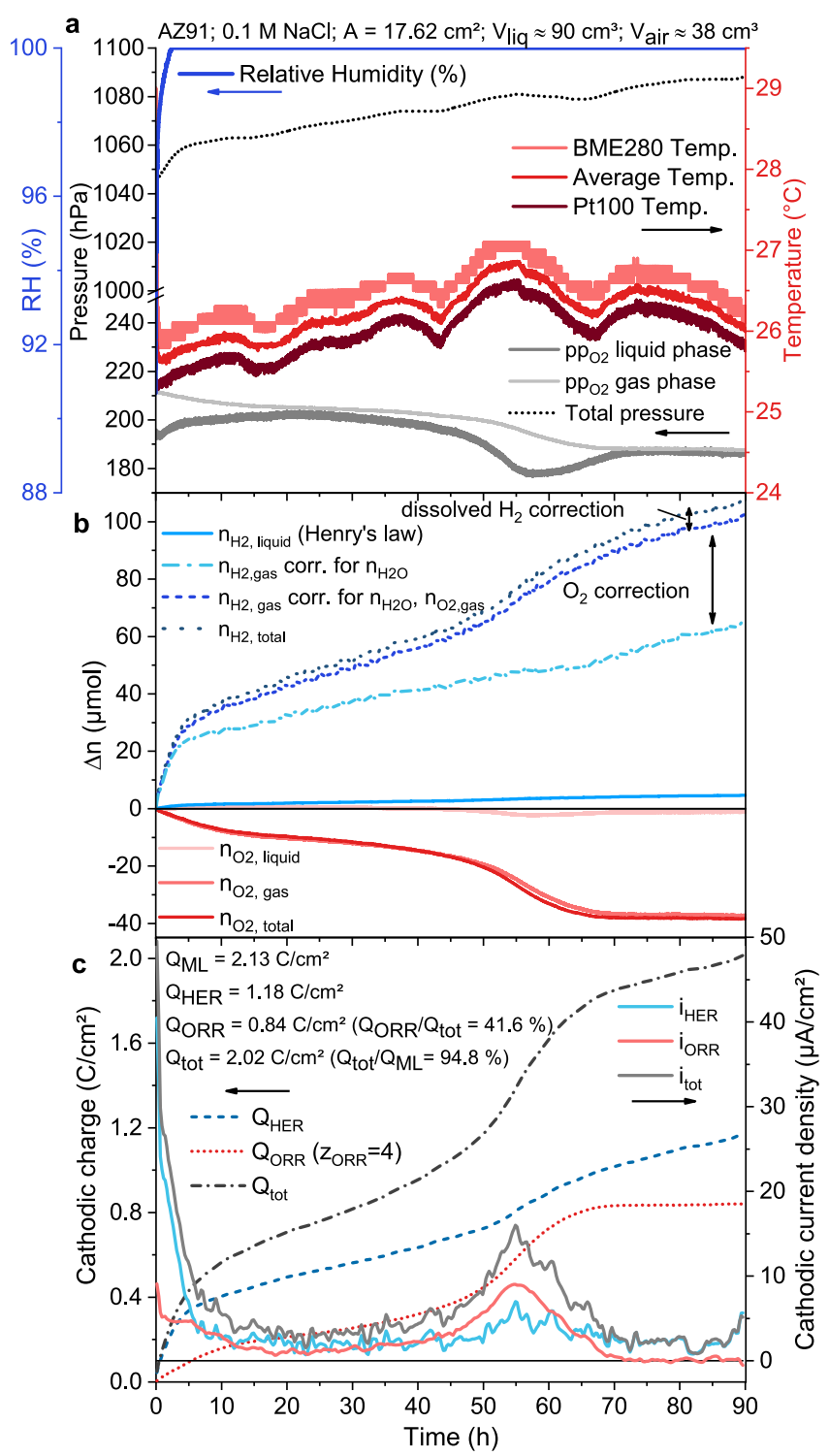

Figure 9. Simultaneous HER and ORR monitoring of AZ91 immersed in $0.1 \mathrm{M} \mathrm{NaCl}$ in the manometric respirometric setup: (a) raw data obtained from the sensors, (b) changes in the number of $\mathrm{H}_{2}$ and $\mathrm{O}_{2}$ in gas and liquid phase, and (c) HER, ORR and total respirometric charge and current density.

of electrolyte by far exceeds the amount of $\mathrm{H}_{2}$ gas detected in the experiments. This makes it difficult to estimate the contribution of dissolved $\mathrm{H}_{2}$ for this setup without additional mass loss tests.

Conversely, the influence of possible $\mathrm{H}_{2}$ dissolution is limited in the volume reduced experiments. As a consequence, more $\mathrm{H}_{2}$ is detected and it is possible to give a good estimate of the amount of dissolved $\mathrm{H}_{2}$ with Henry's law. This shows that the effect of dissolution of $\mathrm{H}_{2}$ should be considered especially for low corrosion rates and high volume of electrolyte. More sensitive and correct measurements of HER rates are possible with a volume reduced gravimetric setup as shown in Figs. 2c, 2d. This comes at the expense of a possible modification of the corrosion mechanism due a faster alkalinization with higher surface area to volume ratio setups.

Regarding the amount of corrosion as determined by solution analysis with ion chromatography it can be observed that this method largely underestimates the amount of corrosion that has occurred. This can be rationalized with the $\mathrm{Mg}^{2+}$ ions that form a corrosion product film on the sample surface and that are not registered by solution analysis. The amount of corrosion products that remained on the sample were estimated with mass gain and 


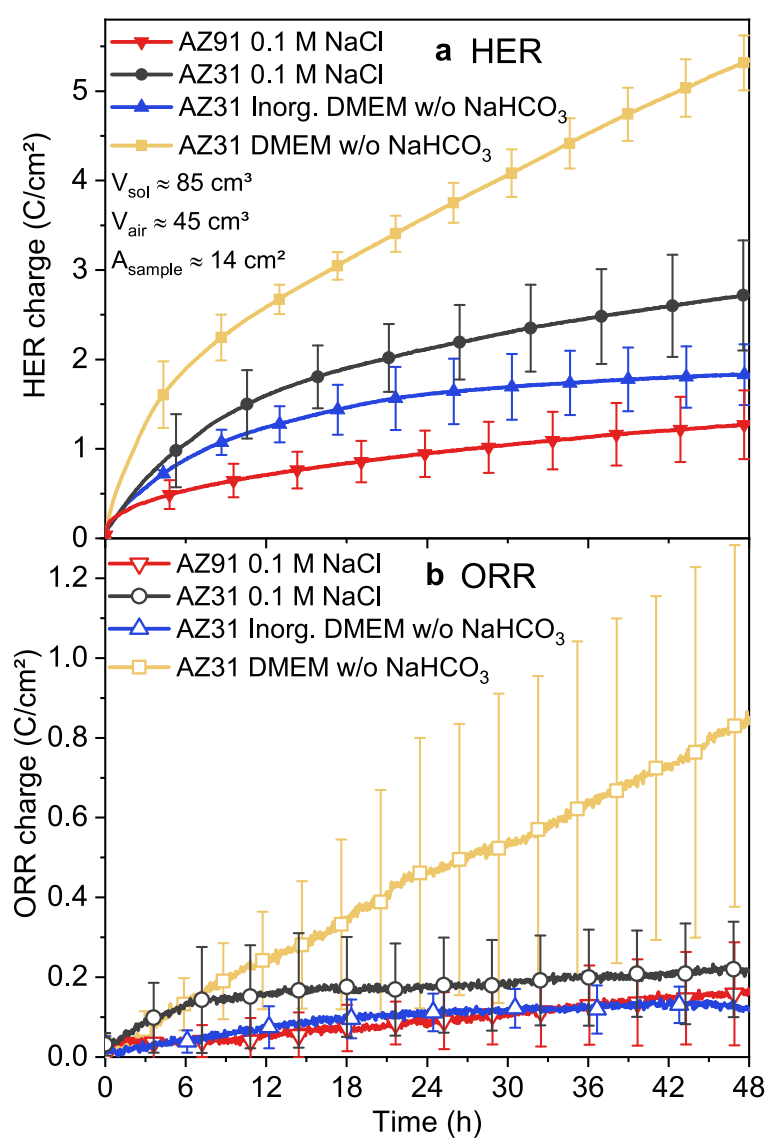

Figure 10. HER (a) and ORR (b) charge curves of $\mathrm{Mg}$ alloys in $0.1 \mathrm{M} \mathrm{NaCl}$, inorganic DMEM w/o $\mathrm{NaHCO}_{3}$ and DMEM w/o $\mathrm{NaHCO}_{3}$ measured with the manometric respirometric setup. Dissolved $\mathrm{H}_{2}$ was considered in the HER charge with a correction based on Henry's law using the actual partial pressure of $\mathrm{H}_{2}$ in the gas phase.

mass loss measurements and assuming that $\mathrm{Mg}(\mathrm{OH})_{2}$ was formed as the dominant corrosion product. From Fig. 7 it can be seen that this estimation gives a good fit of the amount of soluble and insoluble $\mathrm{Mg}^{2+}$ ions with mass loss, especially for AZ31. The remaining discrepancy with AM50 and AZ91 can be explained with the increasing amount of corroded $\mathrm{Al}^{3+}$ ions that were not measured with IC and that were not considered with the corrosion product composition assumption. Compared with the $500 \mathrm{ml}$ samples, the lower electrolyte volume samples exhibited proportionately more $\mathrm{Mg}^{2+}$ ions in the film, which supports the notion of increased protectiveness of the corrosion product film under these conditions.

With only gravimetric HER measurements, one uncertainty remains regarding the role of the ORR in $\mathrm{Mg}$ alloy corrosion under immersion conditions. In Part I of this paper series, for atmospheric corrosion, it was found that ORR can contribute to the cathodic reactions on $\mathrm{Mg}$ alloy corrosion. Already with the gravimetric results in conjunction with mass loss it can be stated that ORR has a minor influence during $48 \mathrm{~h}$ immersion. The addition of an optical $\mathrm{O}_{2}$ sensor that measures $\mathrm{O}_{2}$ partial pressure in the headspace of the gravimetric setup would be a possibility to measure both HER and ORR simultaneously. This measurement configuration was tested on $\mathrm{Zn}$ immersed in $0.1 \mathrm{M} \mathrm{NaCl}$ using the setup in Fig. $2 \mathrm{~d}$ and the results are shown in Fig. 8. Under neutral conditions, ORR is the dominant cathodic reaction of $\mathrm{Zn}$ corrosion. The ORR leads to the removal of $\mathrm{O}_{2}$ from the headspace that can be detected with both the gravimetric measurement and the $\mathrm{O}_{2}$ sensor. The concentration changes of $\mathrm{O}_{2}$ in the liquid phase were not monitored in this experiment. Because the electrolyte was stagnant, the corrosion rate was extremely low in this experiment. While there is some deviation in the signals of the two measurement approaches in the beginning of the experiment, a very good agreement in the ORR rate was found after one day.

One possible source of error is that the optical fiber was not tightly attached to the sensor spot in order not to disturb the gravimetric measurement. The exact position of the optical fiber on the sensor spot could influence the measured $\mathrm{O}_{2}$ pressure. In addition, the $\mathrm{O}_{2}$ sensor measurement is not independent from the gravimetric measurement since any volume change also affects the $\mathrm{O}_{2}$ partial pressure. To study the influence of ORR in $\mathrm{Mg}$ alloy immersion in more detail, it was decided to carry out tests in the constant gas volume manometric setup.

Static manometric experiments.-To demonstrate simultaneous HER and ORR monitoring with the static manometric setup, the results of a $90 \mathrm{~h}$ immersion experiment carried out with AZ91 in $0.1 \mathrm{M} \mathrm{NaCl}$ is shown. The raw data recorded with the different sensors can be seen in Fig. 9a. From the changes in $\mathrm{O}_{2}$ partial pressure in the gas and liquid phase, total pressure, temperature and relative humidity it is possible to calculate the change in the number of $\mathrm{H}_{2}$ and $\mathrm{O}_{2}$ molecules in the gas phase and liquid phase (Fig. 9b). To calculate the number of $\mathrm{H}_{2}$ in the gas phase, the total pressure change is corrected for changes in water vapor pressure and changes in $\mathrm{O}_{2}$ partial pressure. The amount of $\mathrm{H}_{2}$ dissolved in the liquid phase is estimated with Henry's law using the actual partial pressure of $\mathrm{H}_{2}$ in the gas phase. In this special long-term experiment, besides evolving $\mathrm{H}_{2}$, AZ91 also consumes a considerable amount of $\mathrm{O}_{2}$. This can be seen from the decrease in $\mathrm{O}_{2}$ partial pressures and in the decrease in the total number of $\mathrm{O}_{2}$ molecules. In Fig. 9c, the change in the total number of moles of $\mathrm{H}_{2}$ and $\mathrm{O}_{2}$ is converted to an HER and ORR charge assuming $\mathrm{z}_{\mathrm{ORR}}=4$. The derivative of the charge curves results in real-time current density for the two cathodic reactions. This demonstrates that real-time monitoring of both HER and ORR rates is possible simultaneously.

Looking at the comparison of the total respirometric charge with mass loss reveals an excellent correlation. The share of ORR in the cathodic charge for this particular long-term experiment was over $40 \%$. A special phenomenon that was revealed by real-time monitoring in this experiment is that the corrosion rate and especially the ORR rate increased again after an initial period of declining corrosion rate. Parallel optical imaging of the corroding surface (see time-lapse video in supporting information) demonstrates that this event coincides with a branching and multiplication of active corrosion fronts. It can only be speculated that this activation of corrosion fronts was triggered by an increased cathodic activity that supplied the current necessary to drive more anodic fronts. ${ }^{58}$ Since the effect of a second corrosion rate maximum was not reproducible on AZ91, it is possible that a special feature in the microstructure that results from the inhomogeneous casting process was responsible. Subsequently, many of the corrosion fronts came to a stop which leads to decreasing of the HER and ORR rates. Interestingly, afterwards the deposition of a white precipitate can be observed on parts of the sample and no ORR activity was detected anymore. It is possible that the precipitates blocked sites where the ORR was occurring.

In general, the partial pressure of $\mathrm{O}_{2}$ in the liquid phase tends to follow the course of partial pressure in the gas phase, which means that gas exchange is fast enough and the concentration in both phases is in equilibrium. Removal of $\mathrm{O}_{2}$ from the liquid phase can be observed in the parts of the experiments with high $\mathrm{H}_{2}$ evolution rate. $\mathrm{H}_{2}$ gas takes up dissolved $\mathrm{O}_{2}$ and leads to a degassing of the surrounding solution. Eventually though, the bubbles will rise to the gas phase and the solution will again reach equilibrium with the concentration in the gas phase. In the gas-tight chamber, $\mathrm{O}_{2}$ cannot escape the closed system, unless it is really consumed by corrosion. Comparing the changes in the moles of $\mathrm{O}_{2}$ in gas and liquid phase, it becomes obvious that most changes occur in the gas phase. In a stirred solution and for the ratio of gas to liquid volume used in this experiment, it seems that one $\mathrm{O}_{2}$ sensor that measures in the gas 


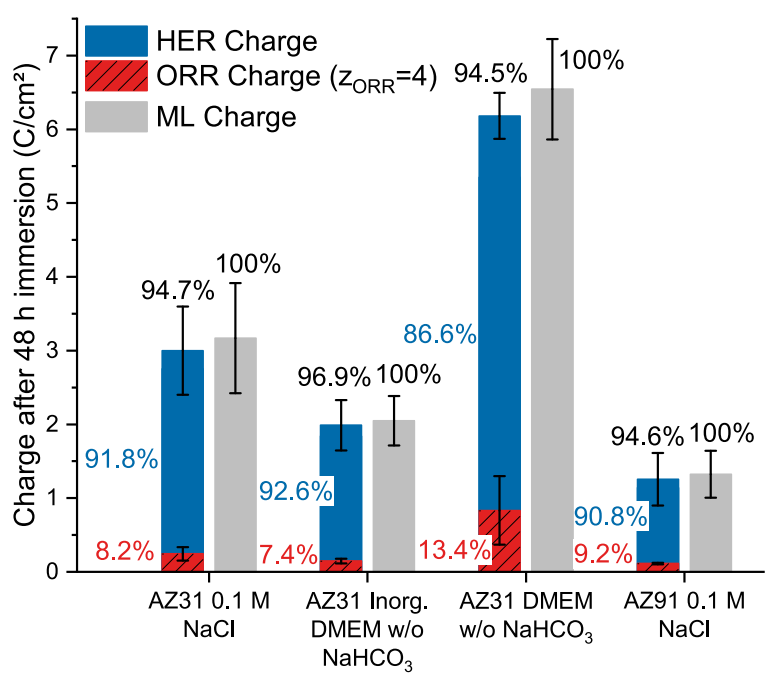

Figure 11. Comparison of the results of the manometric respirometric experiments with mass loss after $48 \mathrm{~h}$ immersion. The relative contribution of $\mathrm{Q}_{\mathrm{HER}} / \mathrm{Q}_{\text {tot }}$ and $\mathrm{Q}_{\mathrm{ORR}} / \mathrm{Q}_{\text {tot }}$ are given in percent in addition to the values of $\mathrm{Q}_{\text {tot }} / \mathrm{Q}_{\mathrm{ML}}$ in percent.

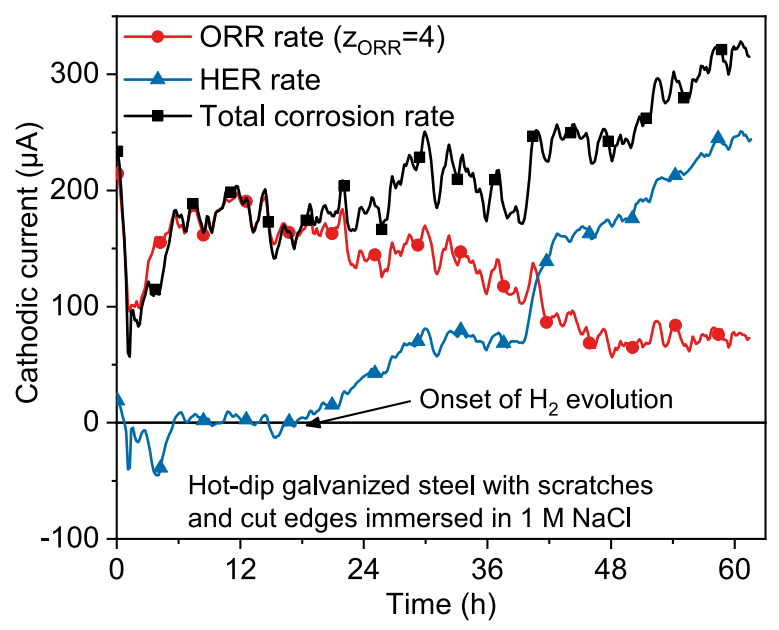

Figure 12. Simultaneous HER and ORR monitoring of a hot-dip galvanized steel sample with scratches and cut edges immersed in $1 \mathrm{M} \mathrm{NaCl}$ solution. A time-lapse video can be found in the supporting information.

phase would to be sufficient to monitor $\mathrm{O}_{2}$ consumption. Since the changes in the moles of $\mathrm{O}_{2}$ in the liquid phase are not very pronounced, this contribution could be calculated with adequate accuracy from the $\mathrm{O}_{2}$ partial pressure in the gas phase.

More manometric experiments of AZ31 and AZ91 Mg alloys were carried out in $0.1 \mathrm{M} \mathrm{NaCl}$, in a solution that contained the inorganic parts of DMEM without $\mathrm{NaHCO}_{3}$ and in DMEM without $\mathrm{NaHCO}_{3}$ for an exposure time of $48 \mathrm{~h}$. The resulting averaged HER and ORR charge curves of multiple replicate samples are depicted in Fig. 10. $\mathrm{NaHCO}_{3}$ was not added to the DMEM electrolyte because of possible interference with the pressure measurements by outgassing $\mathrm{CO}_{2}$. DMEM is a cell culture medium that contains organic molecules such as amino acids, vitamins and glucose as nutrients for cell growth. Unfortunately, this medium favors also the growth of microorganisms and their metabolism can lead to considerable background respiration. The influence of background respiration was determined by parallel experiments without a sample and by testing the solution at the end of the experiment with the sample removed. It was found that the high $\mathrm{pH}$ that evolved due to $\mathrm{Mg}$ corrosion effectively supressed the growth of microorganisms for the duration of the experiment, which is in accordance with literature. ${ }^{41}$

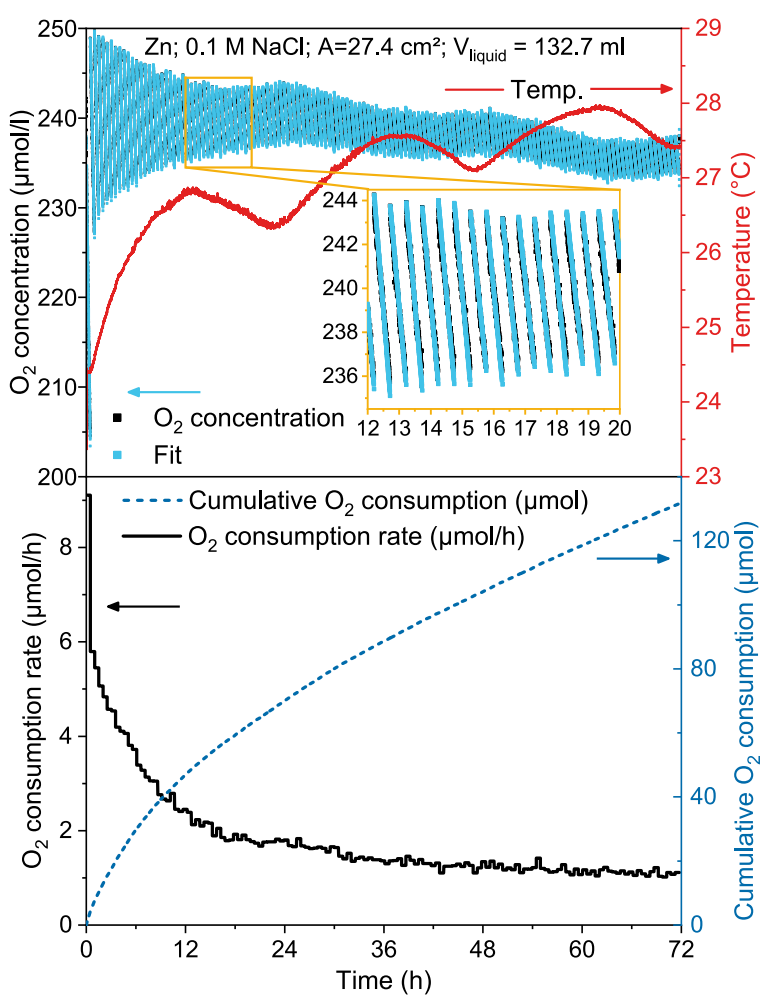

Figure 13. Intermittent-flow respirometric determination of $\mathrm{O}_{2}$ consumption of $\mathrm{Zn}$ immersed in $0.1 \mathrm{M} \mathrm{NaCl}$. The $\mathrm{O}_{2}$ concentration curve shows a sawtooth shape that is the result of alternating 30 min measurement periods and $30 \mathrm{~s}$ flush periods. The $\mathrm{O}_{2}$ consumption rate was extracted from the slopes of the measurement periods.

AZ91 is less susceptible to corrosion in $0.1 \mathrm{M} \mathrm{NaCl}$ compared to AZ31. This trend that was already found with the gravimetric measurements can be confirmed with the manometric method. In addition, with the manometric setup it is possible to quantify the amount of $\mathrm{O}_{2}$ that was consumed due to the ORR in real-time. For $48 \mathrm{~h}$ immersion, the influence of ORR is not as pronounced as in the $90 \mathrm{~h}$ experiment in Fig. 9. However, a small but steady $\mathrm{O}_{2}$ consumption can be resolved with the $\mathrm{O}_{2}$ sensors for all alloys and solutions.

Comparing the influence of the different electrolytes for AZ31, it follows that the HER and ORR rates increase in the order: inorganic DMEM without $\mathrm{NaHCO}_{3}<0.1 \mathrm{M} \mathrm{NaCl}<$ DMEM without $\mathrm{NaHCO}_{3}$. This can be explained, on the one hand, with the formation of corrosion product layers with the ions present in the DMEM medium. For example, it is commonly observed that $\mathrm{Mg}$ in simulated physiological solutions forms an amorphous layer of $(\mathrm{Mg}, \mathrm{Ca})_{\mathrm{x}}\left(\mathrm{PO}_{4}\right)_{\mathrm{y}}\left(\mathrm{CO}_{3}\right)_{\mathrm{z}}(\mathrm{OH})_{\mathrm{i}}$ that can increase the protectiveness afforded to the substrate. ${ }^{59-61}$ On the other hand, it seems that amino acids and the other organic compounds present in the DMEM electrolyte have an accelerating effect on the corrosion rate of AZ31. This could be explained by the chelating interaction of the organic molecules with $\mathrm{Mg}^{2+}-$ or $\mathrm{Ca}^{2+}-$ ions that can encourage $\mathrm{Mg}$ dissolution and retard the formation of insoluble surface layers. ${ }^{62}$

A comparison of the HER, ORR and total respirometric charge with mass loss charge for the different samples is carried out in Fig. 11. A very good agreement between the total respirometric charge and mass loss was found. This implies that reliable real-time monitoring is possible with the manometric respirometric method and that the cumulative amount of HER and ORR charge gives a good measure for the amount of corrosion that has occurred. In general, the contribution of ORR to the total cathodic charge is around $10 \%$. These findings are in line with recent studies that provide evidence for the partial role of ORR in Mg corrosion under 


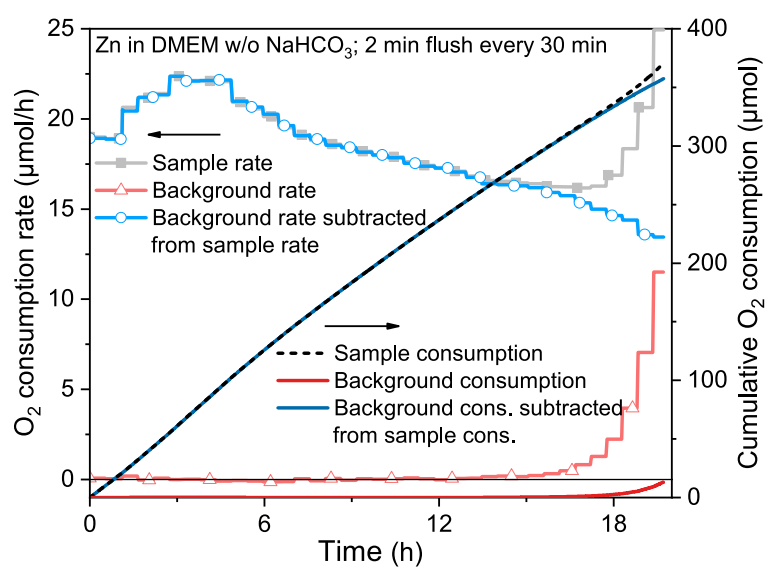

Figure 14. Intermittent-flow experiment of $\mathrm{Zn}$ immersed in DMEM w/o $\mathrm{NaHCO}_{3}$ where the rate of microbial background respiration was determined simultaneously in a parallel chamber without sample. Subtracting the background $\mathrm{O}_{2}$ consumption from the consumption measured in the sample chamber leads to the true $\mathrm{O}_{2}$ consumption of the corroding sample.

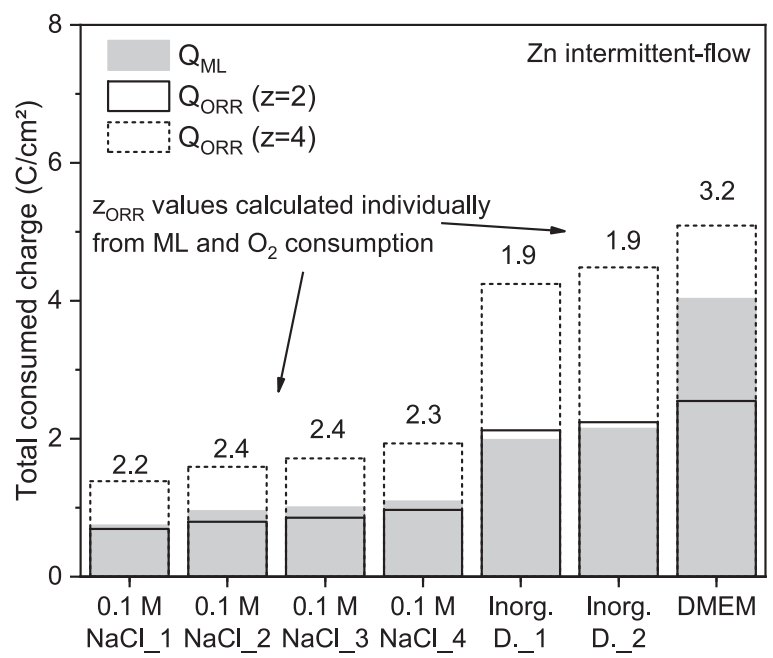

Figure 15. Comparison of the ORR charge determined from $\mathrm{O}_{2}$ consumption with mass loss charge for several intermittent-flow experiments in different electrolytes. The immersion time was $72 \mathrm{~h}$ for $0.1 \mathrm{M} \mathrm{NaCl}$ and inorganic DMEM w/o $\mathrm{NaHCO}_{3}$ and $20 \mathrm{~h}$ for the DMEM w/o $\mathrm{NaHCO}_{3}$ experiment. The ORR charge ranges for $\mathrm{z}_{\mathrm{ORR}}$ values of 2 and 4 are given together with the apparent $\mathrm{z}_{\mathrm{ORR}}$ that was calculated from mass loss and cumulative consumed $\mathrm{O}_{2}$.

immersion conditions. ${ }^{63,64}$ Under the exposure conditions of the present study, no considerable difference of the ORR influence was found for the different $\mathrm{Mg}$ alloys or the different electrolytes. Some scattering between replicate samples was found in the ORR percentage, which can possibly be explained by a variation in the microstructure or in the level of impurities of the samples. To conclude, the influence of ORR in $\mathrm{Mg}$ alloy immersion corrosion cannot be omitted in general. The AZ91 $90 \mathrm{~h}$ experiment in Fig. 9 signifies that there are conditions where the ORR contribution can be substantial.

Another example measurement with the manometric setup was carried out with a hot dipped galvanized steel sample with scratches and cut edges immersed in $1 \mathrm{M} \mathrm{NaCl}$ solution (Fig. 12). A timelapse video can be found in the supplemental material. The onset of visible $\mathrm{H}_{2}$ evolution can be observed after an initial phase of corrosion accompanied by only ORR. Neither Zn nor steel show appreciable amount of HER at open circuit corrosion at this $\mathrm{pH}$ value, so the effect was attributed to cathodic polarization of Fe by the galvanic coupling to $\mathrm{Zn} .{ }^{65}$ The onset of HER could be also followed with the respirometric measurement in real-time. With further immersion time, it was found that the HER rate increased and eventually surpassed the progressively decreasing ORR rate.

Intermittent-flow respirometric experiments.-Intermittent-flow experiments to monitor $\mathrm{O}_{2}$ consumption rates are very well suited to study corrosion systems where ORR is the only cathodic reaction. This method works without a gas phase and monitors the decrease of the dissolved $\mathrm{O}_{2}$ concentration with an optical $\mathrm{O}_{2}$ sensor. Because the solubility of $\mathrm{O}_{2}$ in water is limited, the partial pressure and hence the concentration of dissolved $\mathrm{O}_{2}$ decreases faster than in experiments with a gas phase. This allows for sensitive measurements of $\mathrm{O}_{2}$ consumption but also requires a periodic replenishing of the $\mathrm{O}_{2}$ content in the chamber for long-term monitoring. An example measurement of $\mathrm{Zn}$ corroding in $0.1 \mathrm{M} \mathrm{NaCl}$ is demonstrated in Fig. 13. A series of $30 \mathrm{~min}$. $\mathrm{O}_{2}$ consumption measurement periods was periodically interrupted by $30 \mathrm{~s}$ flushing intervals to replace the electrolyte inside the chamber. The solution inside the chamber was stirred with $200 \mathrm{rpm}$ to avoid bulk $\mathrm{O}_{2}$ concentration gradients. $\mathrm{O}_{2}$ consumption rates were extracted from the slopes of the concentration profiles of each measurement period. Careful inspection of the data and the quality of the fit is crucial in getting reliable results. Temperature imbalance and gas bubbles can skew the results and should be avoided. Integration of the obtained rates leads to a cumulative amount of $\mathrm{O}_{2}$ consumed by the corroding sample.

While background $\mathrm{O}_{2}$ consumption was minimal in the case of $0.1 \mathrm{M} \mathrm{NaCl}$, it became substantial in an experiment of $\mathrm{Zn}$ immersed in DMEM w/o $\mathrm{NaHCO}_{3}$ (Fig. 14). In this intermittent-flow experiment the rate of microbial background respiration was determined simultaneously in a parallel chamber without a sample. After $12 \mathrm{~h}$ immersion an exponential increase of the $\mathrm{O}_{2}$ consumption rate in the background chamber was recorded. This increase in background respiration affects also the rates measured in the sample chamber. Subtracting the background $\mathrm{O}_{2}$ consumption from the consumption in the sample chamber leads to the true $\mathrm{O}_{2}$ consumption of the corroding sample, assuming there was no effect of $\mathrm{Zn}$ corrosion on the background. The experiment was stopped when the background rate became comparable to the consumption rate of the sample.

In addition to $0.1 \mathrm{M} \mathrm{NaCl}$ and DMEM w/o $\mathrm{NaHCO}_{3}$, intermittent-flow experiments were also conducted with inorganic DMEM w/o $\mathrm{NaHCO}_{3}$. The total amount of consumed $\mathrm{O}_{2}$ of these experiments was compared with the charge determined independently by mass loss in Fig. 15. It was found that the ORR charge calculated with $\mathrm{z}_{\mathrm{ORR}}=4$ would largely overestimate the amount of corrosion that has occurred as determined by mass loss. The results suggest that the ORR proceeds to a high extent via the 2-electron mechanism. In fact, many studies agree that the 2-electron ORR mechanism predominates on $\mathrm{Zn}$ covered by oxide or hydroxide surface layers under near neutral conditions. ${ }^{66-70}$ The 2-electron ORR mechanism leads to the generation of $\mathrm{H}_{2} \mathrm{O}_{2}$ that goes into the bulk solution. From a measurement point of view, it is then important whether the produced $\mathrm{H}_{2} \mathrm{O}_{2}$ is stable in the solution or decomposes before or after being flushed out of the measurement chamber. If two $\mathrm{H}_{2} \mathrm{O}_{2}$ molecules decompose to $\mathrm{O}_{2}$ and water inside the chamber, this will contribute to the 4-electron pathway. If the same reaction happens outside the chamber, it will appear like a 2electron pathway mechanism because the generated $\mathrm{O}_{2}$ molecule is out of the reach of the $\mathrm{O}_{2}$ sensor.

The fate of the peroxide intermediate may depend on the catalytic properties of the material where the ORR takes place. Various metals were screened for their selectivity of the 2-electron pathway or the 4-electron pathway with a polarographic method by Delahay. ${ }^{67}$ Furthermore, rotating ring disc electrode (RRDE) ${ }^{68,69}$ experiments or scanning electrochemical microscopy (SECM) ${ }^{37,71}$ approaches enable one to probe for the amount of $\mathrm{H}_{2} \mathrm{O}_{2}$ to elucidate the ORR mechanism. Even for one material the potential or $\mathrm{pH}$ dependent surface state can change the ORR mechanism. ${ }^{66,68,69}$ On 


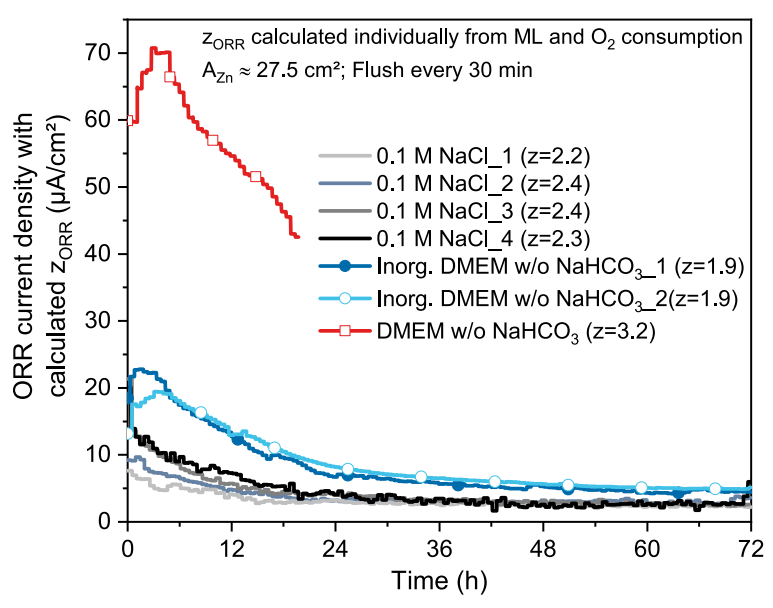

Figure 16. Real-time ORR current densities calculated from the slopes of the $\mathrm{O}_{2}$ consumption curves in intermittent-flow experiments of $\mathrm{Zn}$ immersed in different electrolytes. The apparent $\mathrm{z}_{\mathrm{ORR}}$ was used for the calculation of ORR rates.

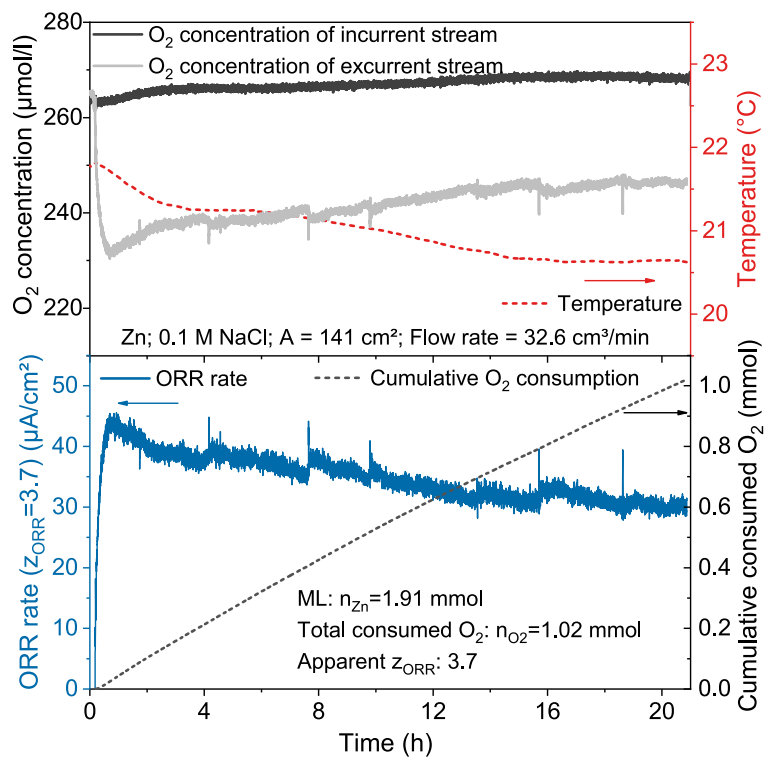

Figure 17. Continuous flow-through respirometric monitoring of $\mathrm{O}_{2}$ consumption of a $\mathrm{Zn}$ sample corroding in $0.1 \mathrm{M} \mathrm{NaCl}$.

$\mathrm{Pt}$, the mass transport rate and the presence of adsorbing species in the electrolyte can influence whether $\mathrm{H}_{2} \mathrm{O}_{2}$ gets further reduced on the electrode or desorbs and can diffuse away. ${ }^{72}$ Other influences that affect the stability of $\mathrm{H}_{2} \mathrm{O}_{2}$, once it reaches the bulk, are peroxide concentration, $\mathrm{pH}$ and temperature of the solution, as well as the presence of homogeneous or heterogenous catalysts that favor $\mathrm{H}_{2} \mathrm{O}_{2}$ decomposition. ${ }^{71,73,74}$ This can be for example the presence of $\mathrm{Fe}^{3+-}$ ions, ${ }^{75} \mathrm{Cu}^{2+}$-ions, ${ }^{73}$ or $\mathrm{I}^{-}$-ions. ${ }^{74}$

A color test based on a specific detection reaction for the presence of $\mathrm{H}_{2} \mathrm{O}_{2}$ was carried out by adding $\mathrm{TiOSO}_{4}$ dissolved in dilute sulfuric acid to a $0.1 \mathrm{M} \mathrm{NaCl}$ solution where $\mathrm{Zn}$ was corroding for $24 \mathrm{~h}^{76}$ This test showed a clear yellow color that is the result of the formation of a peroxotitanium complex. ${ }^{77}$ The positive test confirms the presence of $\mathrm{H}_{2} \mathrm{O}_{2}$ in the bulk solution that was produced by $\mathrm{Zn}$ corrosion. It is therefore concluded that, under the experimental conditions of the intermittent-flow experiment, $\mathrm{H}_{2} \mathrm{O}_{2}$ was produced as a stable product. $\mathrm{H}_{2} \mathrm{O}_{2}$ entered the bulk solution in the chamber without extensive further reduction to water or decomposition. Periodic flushing led to a dilution with the electrolyte from the reservoir and prevented $\mathrm{H}_{2} \mathrm{O}_{2}$ accumulation to a level where decomposition was fast enough to enable a 4-electron ORR pathway.

An apparent number of transferred electrons $\mathrm{z}_{\mathrm{ORR}}$ was calculated, assuming that both mass loss and respirometry give reliable values of the number of oxidized $\mathrm{Zn}$ ions and number of reduced $\mathrm{O}_{2}$ molecules, respectively. The calculated values, given in Fig. 15, are close to 2 for $0.1 \mathrm{M} \mathrm{NaCl}$ and inorganic DMEM. The $\mathrm{Zn}$ experiment with DMEM electrolyte showed a higher $\mathrm{z}_{\mathrm{ORR}}$ value of 3.2. A possible explanation for the higher value is that the presence of organic molecules favored the catalytic decomposition of peroxide. In addition, in contrast to the other electrolytes, DMEM contains a small amount of $\mathrm{Fe}^{3+}$-ions that could have catalyzed the decomposition of $\mathrm{H}_{2} \mathrm{O}_{2}$. If the ORR mechanism changes during exposure time, also the shorter duration of the DMEM experiment could explain the higher $z_{O R R}$ value. To compare the real-time corrosion rates of $\mathrm{Zn}$ in the different solutions, it was decided to evaluate the ORR rates with $z_{O R R}$ values that were calculated individually for each sample based on mass loss and cumulative $\mathrm{O}_{2}$ consumption. From the current density curves in Fig. 16 it follows that $0.1 \mathrm{M} \mathrm{NaCl}$ has the lowest $\mathrm{Zn}$ corrosion rate. The ORR rates are higher in inorganic DMEM and greatly accelerated in DMEM with organic constituents. The origin of this behavior, i.e. the role of the different components in the complex electrolytes on the corrosion mechanism remains to be elucidated.

It is interesting to note that a contribution of the 2-electron process was not found under atmospheric corrosion conditions in Part I of the paper series. For $\mathrm{Zn}$ corroding under deliquesced $\mathrm{NaCl}$ droplets, the data suggests that ORR proceeds solely through the 4-electron process. The situation with a thin electrolyte layer probably favors the decomposition or further reduction of peroxide. Future work should focus on the effect of different experimental parameters on the contribution of the peroxide pathway for different materials.

Continuous flow-through respirometric measurement.-Pure $\mathrm{Zn}$ in a respirometric chamber was exposed to a continuous stream of $0.1 \mathrm{M} \mathrm{NaCl}$ solution in a flow-through experiment (Fig. 17). Realtime $\mathrm{O}_{2}$ consumption rates due to corrosion were determined from the concentration difference of the incurrent and excurrent stream and the flow-rate. Integrating the rates results in the cumulative amount of consumed $\mathrm{O}_{2}$. Similar to the intermittent-flow experiments, it is possible to calculate the number of exchanged electrons in the ORR using the mass loss results. For this experiment, a $z_{O R R}$ value of 3.7 was found which is much closer to the 4-electron pathway compared to the intermittent-flow experiments in the same electrolyte. ORR rates plotted in Fig. 17 were calculated with this apparent $z_{O R R}$ value. Differences in the experimental conditions that could possibly explain the different $\mathrm{z}_{\mathrm{ORR}}$ value found in the continuous flow setup compared to intermittent-flow experiments include the following points. Due to a higher surface area to chamber volume ratio it can be expected that a higher peroxide concentration builds up in the chamber. The reduced flow velocity in the flowthrough experiment favors a more laminar type of electrolyte flow over the corroding surface. Because of the limited mixing of the solution in the vicinity of the sample surface with the bulk solution, this situation resembles the atmospheric corrosion scenario. As a consequence, It can be hypothesized that the slower mass transfer conditions increases the possibility of further $\mathrm{H}_{2} \mathrm{O}_{2}$ reduction or decomposition. This example however demonstrates that mechanisms of corrosion reactions can be highly sensitive to details in the experimental setup. This clearly illustrates the necessity to collect detailed data under different exposure conditions, such as is possible by the here introduced methodologies.

\section{Conclusions}

Our work demonstrates with different respirometric methods that immersion corrosion kinetics can be monitored non-destructively and in real-time. The respirometric method is recommended as a 
valuable addition to the well-established electrochemical techniques to study corrosion processes. As conclusions we find:

- Gravimetric real-time measurement of the evolved $\mathrm{H}_{2}$ volume enables sensitive monitoring of HER rates. $\mathrm{H}_{2}$ dissolved into the electrolyte can pose difficulties in accurate measurement of corrosion resistant alloys in high volume of electrolyte. Volume reduced and closed setups were presented that allow for a correction of the amount of dissolved $\mathrm{H}_{2}$ with Henry's law. With a headspace setup, gravimetric ORR monitoring is possible.

- A combined pressure sensor and optical $\mathrm{O}_{2}$ sensor manometric setup was presented that allows for real-time monitoring of HER, ORR or both reactions simultaneously. The method was applied to study the effect of different physiological solutions on $\mathrm{Mg}$ alloy corrosion and to monitor ORR and HER rates of a scratched $\mathrm{Zn}$ coated steel.

- The gravimetric and manometric respirometric methods were validated by an excellent correlation between the total cathodic charge and mass loss.

- It was shown that $\mathrm{O}_{2}$ is consumed during $\mathrm{Mg}$ alloy corrosion also under immersion conditions. Under the experimental conditions studied, the share of ORR was around $10 \%$ of the total cathodic charge. In a longer-term immersion experiment with AZ91, over $40 \%$ ORR corrosion was detected. The influence of ORR should be taken into account in future studies.

- The concepts of intermittent-flow and flow-through respirometry were successfully adapted in order to monitor $\mathrm{O}_{2}$ consumption rates in corrosion systems were ORR is the dominant reaction. Example measurements with $\mathrm{Zn}$ in different physiological solutions were presented.

- For $\mathrm{Zn}$, the ORR mechanism can lead to the generation of $\mathrm{H}_{2} \mathrm{O}_{2}$ as a stable product according to a 2-electron ORR pathway. Thus, the conversion of $\mathrm{O}_{2}$ consumption rates to ORR corrosion rates is not straightforward. More work is needed to identify the contributions of the ORR pathways for different metals under various experimental conditions.

\section{Acknowledgments}

M.P.B. gratefully acknowledges financial support by the German Research Foundation (DFG) via the research training group GRK 1896. The authors thank Martin Kolacyak for technical support.

\section{ORCID}

M. G. Strebl (iD https://orcid.org/0000-0003-2518-4558

M. P. Bruns (iD https://orcid.org/0000-0002-9092-9053

S. Virtanen (1D https://orcid.org/0000-0002-7179-7593

\section{References}

1. M. Strebl, M. Bruns, and S. Virtanen, J. Electrochem. Soc., 167, 21510 (2020).

2. M. Meeusen, L. Zardet, A. M. Homborg, M. Lekka, F. Andreatta, L. Fedrizzi, B. Boelen, H. Terryn, and J. M. C. Mol, J. Electrochem. Soc., 166, C3220 (2019)

3. ISO 8407, Corrosion of Metals and Alloys - Removal of Corrosion Products from Corrosion test Specimens (International Organization for Standardization) (2009).

4. R. Schumacher, A. Müller, and W. Stöckel, J. Electroanal. Chem. Interfacial Electrochem., 219, 311 (1987)

5. D. Jope, J. Sell, H. W. Pickering, and K. G. Weil, J. Electrochem. Soc., 142, 2170 (1995)

6. B. K. Nash and R. G. Kelly, J. Chromatogr. A, 602, 135 (1992).

7. K. Ogle and S. Weber, J. Electrochem. Soc., 147, 1770 (2000).

8. K. Ogle, Corrosion, 75, 1398 (2019).

9. S. Cherevko and K. J. J. Mayrhofer, "Encyclopedia of interfacial chemistry: Surface science and electrochemistry." ed. K. Wandelt (Elsevier, Amsterdam, Netherlands, Oxford, UK, Cambidge, USA) 326 (2018).

10. N. Homazava, A. Ulrich, and U. Krähenbühl, Spectrochim. Acta, Part B, 63, 777 (2008)

11. L. I. Stephens, S. C. Perry, S. M. Gateman, R. Lacasse, R. Schulz, and J. Mauzeroll, J. Electrochem. Soc., 164, E3576 (2017).

12. M. Esmaily, J. E. Svensson, S. Fajardo, N. Birbilis, G. S. Frankel, S. Virtanen, R. Arrabal, S. Thomas, and L. G. Johansson, Prog. Mater Sci., 89, 92 (2017).

13. T. T. M. Tran, B. Tribollet, and E. M. M. Sutter, Electrochim. Acta, 216, 58 (2016)

14. M. Curioni, Electrochim. Acta, 120, 284 (2014).
15. C. Laurent, F. Scenini, T. Monetta, F. Bellucci, and M. Curioni, Npj Mater Degrad, 1, 25 (2017)

16. Y. Baek and G. S. Frankel, J. Electrochem. Soc., 150, B1 (2003).

17. K. Ogle, M. Serdechnova, M. Mokaddem, and P. Volovitch, Electrochim. Acta, 56, 1711 (2011).

18. J. R. Scully, Corrosion, 56, 199 (2000)

19. K. B. Oldham and F. Mansfeld, Corros. Sci., 13, 813 (1973).

20. J. F. Steffensen, Fish Physiology and Biochemistry, 6, 49 (1989).

21. J. R. B. Lighton and L. G. Halsey, "Comparative biochemistry and physiology." Part A, Molecular \& Integrative Physiology, 158, 265 (2011).

22. K. J. Bradford, P. Bello, J.-C. Fu, and M. Barros, Seed Science and Technology, 41 420 (2013)

23. A. P. Scafaro et al., Plant Methods, 13, 16 (2017).

24. A. Krajčová, T. Urban, D. Megvinet, P. Waldauf, M. Balík, J. Hlavička, P. Budera, L. Janoušek, E. Pokorná, and F. Duška, PLoS One, 15, e0226142 (2020).

25. S. Djafarzadeh and S. M. Jakob, J. Vis. Exp., 54985 (2017).

26. H. Spanjers and P. A. Vanrolleghem, Experimental Methods in Wastewater Treatment, ed. M. C. M. van Loosdrecht, P. H. Nielsen, C. M. Lopez-Vazquez, and D. Brdjanovic (IWA Publishing) 133 (2016).

27. T. D. Clark, E. Sandblom, and F. Jutfelt, The Journal of Experimental Biology, 216 2771 (2013).

28. L. Cáceres, L. Herrera, and T. Vargas, Corrosion, 63, 722 (2007).

29. Y. Hisamatsu and N. Masuko, Corrosion Engineering Digest, 18, 399 (1969).

30. P. van Rysselberghe, J. M. McGee, A. H. Gropp, R. D. Williams, and P. Delahay, Corrosion, 6, 105 (1950).

31. E. J. Reardon, Environmental Science \& Technology, 29, 2936 (1995)

32. S. V. Lamaka, B. Vaghefinazari, D. Mei, R. P. Petrauskas, D. Höche, and M. L. Zheludkevich, Corros. Sci., 128, 224 (2017).

33. I. Katsounaros, W. B. Schneider, J. C. Meier, U. Benedikt, P. U. Biedermann, A. A. Auer, and K. J. J. Mayrhofer, Phys. Chem. Chem. Phys., 14, 7384 (2012).

34. H. S. Wroblowa, Yen Chi-Pan, and G. Razumney, J. Electroanal. Chem. Interfacial Electrochem., 69, 195 (1976).

35. M. Prestat, F. Vucko, B. Lescop, S. Rioual, F. Peltier, and D. Thierry, Electrochim Acta, 218, 228 (2016).

36. E. Yeager, Electrochim. Acta, 29, 1527 (1984).

37. C. M. Sánchez-Sánchez and A. J. Bard, Anal. Chem., 81, 8094 (2009).

38. M. B. S. Svendsen, P. G. Bushnell, and J. F. Steffensen, Journal of Fish Biology, 88, 26 (2016).

39. G. G. Rodgers, P. Tenzing, and T. D. Clark, Journal of fish biology, 88, 65 (2016).

40. T. S. Rao, Aquatic Ecology, 44, 463 (2010).

41. H. Qin, Y. Zhao, M. Cheng, Q. Wang, Q. Wang, J. Wang, Y. Jiang, Z. An, and $\mathrm{X}$. Zhang, RSC Adv., 5, 21434 (2015).

42. M. Stratmann, Ber. Bunsenges. Phys. Chem., 94, 626 (1990).

43. S. Fajardo and G. S. Frankel, J. Electrochem. Soc., 162, C693 (2015).

44. M. Grabowski and S. Virtanen, Corrosion, 73, 563 (2017).

45. M. Strebl and S. Virtanen, J. Electrochem. Soc., 166, C3001 (2019).

46. H. E. Garcia and L. I. Gordon, Limnol. Oceanogr., 37, 1307 (1992).

47. B. Jähne and H. Haußecker, Annual Review of Fluid Mechanics, 30, 443 (1998).

48. P. S. Liss and L. Merlivat, The Role of Air-Sea Exchange in Geochemical Cycling, ed. P. Buat-Ménard (Dordrecht, Springer, Netherlands) p. 113 (1986).

49. P. S. Liss and D. Sea, Research and Oceanographic Abstracts, 20, 221 (1973).

50. A. Pauss, R. Samson, S. Guiot, and C. Beauchemin, Biotechnol. Bioeng., 35, 492 (1990)

51. A. J. Niimi, J. Fish. Res. Board Can., 35, 1265 (1978).

52. J. Han and K. Ogle, J. Electrochem. Soc., 166, C3068 (2019).

53. V. Wagener and S. Virtanen, Corrosion, 73, 1413 (2017).

54. R. SanderHenry's Law Constants, NIST Standard Reference Database Number 69 (Gaithersburg) (2018)

55. L. G. Bland, L. C. Scully, and J. R. Scully, Corrosion, 73, 526 (2017)

56. O. Lunder, J. E. Lein, T. K. Aune, and K. Nisancioglu, Corrosion, 45, 741 (1989).

57. M. Grimm, A. Lohmüller, R. F. Singer, and S. Virtanen, Corros. Sci., 155, 195 (2019).

58. Y. Yang, F. Scenini, and M. Curioni, Electrochim. Acta, 198, 174 (2016).

59. R. Rettig and S. Virtanen, Journal of biomedical materials research. Part A, 88, 359 (2009)

60. I. Marco, F. Feyerabend, R. Willumeit-Römer, and O. van der Biest, Materials Science and Engineering: C, 62, 68 (2016).

61. V. Wagener and S. Virtanen, Materials Science and Engineering: C, 63, 34 (2016).

62. A. Yamamoto and S. Hiromoto, Materials Science and Engineering: C, 29, 1559 (2009).

63. E. L. Silva, S. V. Lamaka, D. Mei, and M. L. Zheludkevich, ChemistryOpen, 7, 664 (2018).

64. C. Wang, D. Mei, G. Wiese, L. Wang, M. Deng, S. V. Lamaka, and M. L. Zheludkevich, npj Mater Degrad, 4, 42 (2020).

65. E. Tada and H. Kaneko, ISIJ Int., 51, 1882 (2011).

66. H. S. Wroblowa and S. B. Qaderi, J. Electroanal. Chem. Interfacial Electrochem., 295, 153 (1990).

67. P. Delahay, J. Electrochem. Soc., 97, 198 (1950)

68. H. Dafydd, D. A. Worsley, and H. N. McMurray, Corros. Sci., 47, 3006 (2005).

69. K. G. Boto and L. F. G. Williams, J. Electroanal. Chem. Interfacial Electrochem. 77, 1 (1977).

70. A. P. Yadav, A. Nishikata, and T. Tsuru, J. Electroanal. Chem., 585, 142 (2005).

71. Q. Zhang, P. Liu, Z. Zhu, J. Zhang, and F. Cao, Corros. Sci., 164, 108312 (2020). 
72. I. Katsounaros, W. B. Schneider, J. C. Meier, U. Benedikt, P. U. Biedermann, A. Cuesta, A. A. Auer, and K. J. J. Mayrhofer, "Physical chemistry chemical physics." PCCP, 15, 8058 (2013).

73. E. Y. Yazici and H. Deveci, Proceedings of the XIIth. International Mineral Processing Symposium, ed. Ö. Y. Gülsoy, L. Ş. Ergün, N. M. Can, and İ. B. Çelik (2010).
74. T. W. Haas, Kinetics of the Uncatalyzed, Alkaline Decomposition of Hydrogen Peroxide, (1960).

75. C. Walling and A. Goosen, JACS, 95, 2987 (1973).

76. C. N. Satterfield and A. H. Bonnell, Anal. Chem., 27, 1174 (1955).

77. G. Schwarzenbach, J. Muehlebach, and K. Mueller, Inorg. Chem., 9, 2381 (1970). 